\title{
Diagnosis of primary ciliary dyskinesia: discrepancy according to different algorithms
}

\author{
Mirjam Nussbaumer ${ }^{1,2}$, Elisabeth Kieninger ${ }^{1,2}$, Stefan A. Tschanz $\mathbb{1}^{3}$, Sibel T. Savas ${ }^{1,2}$, Carmen Casaulta ${ }^{1,2}$,

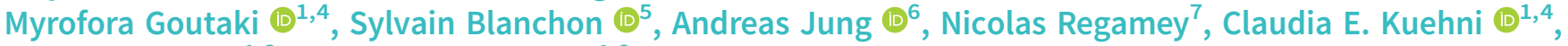 \\ Philipp Latzin (10) ${ }^{1,2}$ and Loretta Müller $\mathbb{1}^{1,2}$ on behalf of the Swiss PCD Research Group
}

${ }^{1}$ Division of Paediatric Respiratory Medicine and Allergology, Dept of Paediatrics, Inselspital, Bern University Hospital, University of Bern, Bern, Switzerland. ${ }^{2}$ Dept of BioMedical Research (DBMR), University of Bern, Bern, Switzerland. ${ }^{3}$ Insitute of Anatomy, University of Bern, Bern, Switzerland. ${ }^{4}$ Institute of Social and Preventive Medicine, University of Bern, Bern, Switzerland. ${ }^{5}$ Dept Woman-MotherChild, Service of Pediatrics, Pediatric Pulmonology and Cystic Fibrosis Unit, Lausanne University Hospital and University of Lausanne, Lausanne, Switzerland. ${ }^{6}$ Division of Respiratory Medicine, University Children's Hospital Zurich, Zurich, Switzerland. ${ }^{7}$ Division of Paediatric Pulmonology, Children's Hospital Lucerne, Lucerne, Switzerland.

Corresponding author: Loretta Müller (Loretta.mueller@insel.ch)
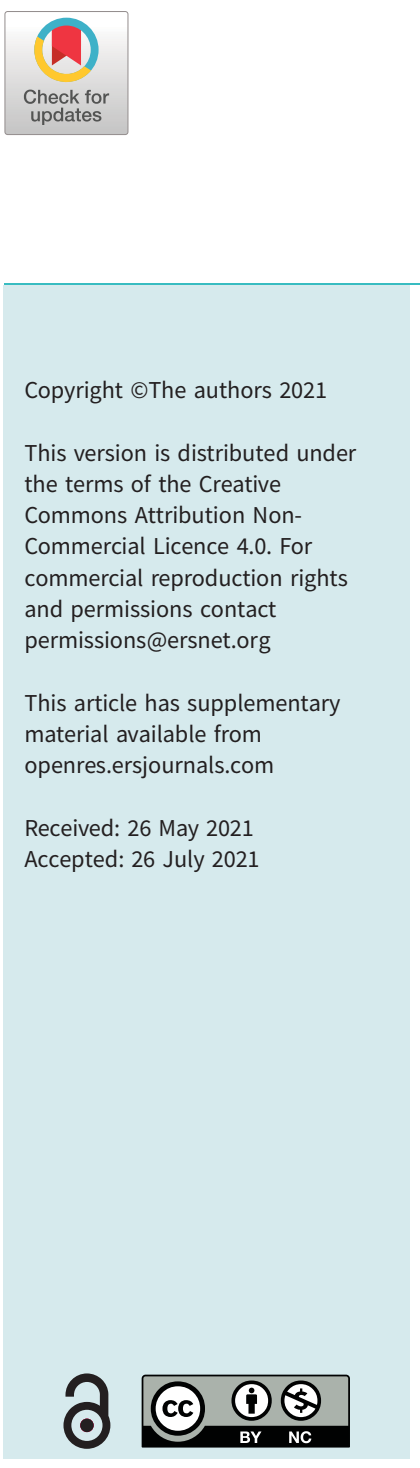

Shareable abstract (@ERSpublications)

There is no gold standard test for diagnosing PCD. The use of existing diagnostic algorithms leads to contradicting results in many patients ( $15 \%$ in this study). Thus, an updated and internationally harmonised diagnostic guideline is needed. https://bit.ly/2U19Vvq

Cite this article as: Nussbaumer M, Kieninger E, Tschanz SA, et al. Diagnosis of primary ciliary dyskinesia: discrepancy according to different algorithms. ERJ Open Res 2021; 7: 00353-2021 [DOI: 10.1183/23120541.00353-2021].

\section{Abstract}

Background Diagnosis of primary ciliary dyskinesia (PCD) is challenging since there is no gold standard test. The European Respiratory (ERS) and American Thoracic (ATS) Societies developed evidence-based diagnostic guidelines with considerable differences.

Objective We aimed to compare the algorithms published by the ERS and the ATS with each other and with our own PCD-UNIBE algorithm in a clinical setting. Our algorithm is similar to the ERS algorithm with additional immunofluorescence staining. Agreement (Cohen's $\kappa$ ) and concordance between the three algorithms were assessed in patients with suspicion of PCD referred to our diagnostic centre.

Results In 46 out of 54 patients (85\%) the final diagnosis was concordant between all three algorithms (30 PCD negative, 16 PCD positive). In eight patients (15\%) PCD diagnosis differed between the algorithms. Five patients (9\%) were diagnosed as PCD only by the ATS, one (2\%) only by the ERS and PCD-UNIBE, one (2\%) only by the ATS and PCD-UNIBE, and one (2\%) only by the PCD-UNIBE algorithm. Agreement was substantial between the ERS and the ATS ( $\kappa=0.72,95 \%$ CI 0.53-0.92) and the ATS and the PCD-UNIBE $(\kappa=0.73,95 \%$ CI $0.53-0.92)$ and almost perfect between the ERS and the PCD-UNIBE algorithms ( $\kappa=0.92,95 \%$ CI $0.80-1.00)$.

Conclusion The different diagnostic algorithms lead to a contradictory diagnosis in a considerable proportion of patients. Thus, an updated, internationally harmonised and standardised PCD diagnostic algorithm is needed to improve diagnostics for these discordant cases.

\section{Introduction}

Primary ciliary dyskinesia (PCD) is a rare genetic disease with an incidence of 1:10 000 to 1:15 000 in Europe [1]. To date genetic variants in $\sim 50$ genes are known to cause PCD [2], mainly with defects in motile cilia of the respiratory epithelium and spermatic flagella [3]. This leads to phenotypic variability with situs inversus and infertility found frequently [4]. Clinical symptoms mostly start during the neonatal period including neonatal respiratory distress, chronic wet cough, perennial rhinosinusitis, recurrent respiratory tract infections leading to bronchiectasis and serous otitis media with hearing impairment [3, 4].

The diagnosis of PCD is challenging since there is no "gold standard" test [7, 8]. Currently, the diagnosis requires a combination of different investigations: nasal nitric oxide (nNO) flow measurement, ciliary 
motion analysis by high-speed videomicroscopy (HSVM), ciliary (ultra)structure analysis by transmission electron microscopy (TEM) and immunofluorescence staining, and genetic analysis. Additionally, airliquid-interface (ALI) cell cultures can be helpful to differentiate PCD from secondary dyskinesia [3, 5, 6]. However, these methods require high levels of expertise, are expensive and their availability varies among diagnostic centres even within a country.

Both the European Respiratory Society (ERS) in 2017 [5] and the American Thoracic Society (ATS) in 2018 [7] published guidelines suggesting diagnostic algorithms. However, these guidelines suggest different diagnostic approaches [8]. The evidence-based ERS guideline focuses on using nNO, HSVM, TEM and genetic testing and distinguishes four diagnostic categories: i) PCD positive (biallelic pathogenic or likely pathogenic variants in a PCD-associated gene or hallmark TEM defect); ii) PCD highly likely (suggestive HSVM and low nNO); iii) PCD highly unlikely; and iv) inconclusive ("consider additional testing and recall patients for testing as new methods become available”) [5, 9]. In contrast, the ATS consensus statement focuses on nNO measurement as primary analysis, followed by genetic panel testing ( $>12$ genes) and TEM. Final categories for this algorithm are: (i) PCD diagnosed and (ii) PCD not diagnosed. Both algorithms have been compared theoretically [8, 10, 11], but a direct comparison using clinical data has not been done yet. In our study, we thus aimed to compare final diagnoses according to these two existing PCD diagnostic algorithms and compare them to the outcome according to the diagnostic algorithm used at our PCD-UNIBE diagnostic centre in a clinical setting using patients' data.

Methods

\section{Study design}

This study compares the outcome of PCD diagnostic testing according to three different diagnostic algorithms - the ERS, the ATS and our centre's (PCD-UNIBE) algorithm (figure 1). We included all patients referred to our comprehensive PCD-UNIBE diagnostic centre at the University Children's Hospital, Inselspital Bern, Switzerland between January 2018 and December 2020 with sufficient data to allow for a conclusive decision on PCD diagnosis based on all three algorithms. Specifically, we included only patients with detailed data on clinical symptoms (all categories of the ATS algorithm), nNO of sufficient quality, and HSVM and immunofluorescence results (not performed for one patient since ciliary beating pattern in HSVM was normal and the clinical suspicion was low). HSVM after cell culture was performed if the cells grew successfully; TEM and genetics were performed if required for a decision based on the PCD-UNIBE algorithm. The study was approved by the Ethics Committee of the Canton Bern, Switzerland (reference number 2018-02155). We obtained written informed consent from all participants or their parents.

\section{Diagnostic algorithm of the PCD-UNIBE centre Description of the algorithm and definition of a positive PCD diagnosis}

We developed a new diagnostic algorithm at the PCD-UNIBE diagnostic centre (figure 1 and figure 2) applied to all patients referred for PCD diagnosis. It is based on the ERS task force guideline for PCD diagnosis [5] and the international consensus guideline for reporting TEM results (BEAT-PCD TEM criteria) [12], additionally including immunofluorescence [13] and ALI cell culture as standard procedure for all brushing samples [14, 15]. Basic investigations are identical for each patient and include nasal brushing with HSVM (fresh and ALI) and immunofluorescence (preferably from ALI cell cultures). Depending on clinical presentation [16] and the results of the basic investigations, we additionally consider TEM and further immunofluorescence stainings. Genetic analysis is done for each patient with a high clinical suspicion, even if the results of the other methods were non-suggestive. An interdisciplinary diagnostic board including clinicians, diagnostic research specialists and lab technicians makes decisions on supplementary investigations.

Results concerning PCD diagnosis are interpreted as follows (figure 2): patients with a class 1 (hallmark) TEM defect and/or biallelic pathogenic or likely pathogenic variants in PCD-associated genes are diagnosed as "PCD positive" [5, 12]. Patients with a PCD-suggestive HSVM, a structural protein missing in immunofluorescence and/or a TEM class 2 defect result are given the diagnosis "PCD highly likely". Patients with no suggestive findings in either method are classified as "PCD highly unlikely" and patients who refuse further needed testing or when further testing is not possible are classified "inconclusive”.

In our study, we consider the categories "PCD positive" and "PCD highly likely" of the ERS and the PCD-UNIBE algorithms and the category "PCD diagnosed" of the ATS algorithms as confirmed PCD. Clinically, all confirmed PCD cases are treated equally. Further, we consider the diagnostic outcome "PCD highly unlikely" of the ERS and the PCD-UNIBE algorithms and "PCD not diagnosed" of the ATS algorithm as PCD excluded, even though we are aware that PCD can never be formally excluded. 
ERS

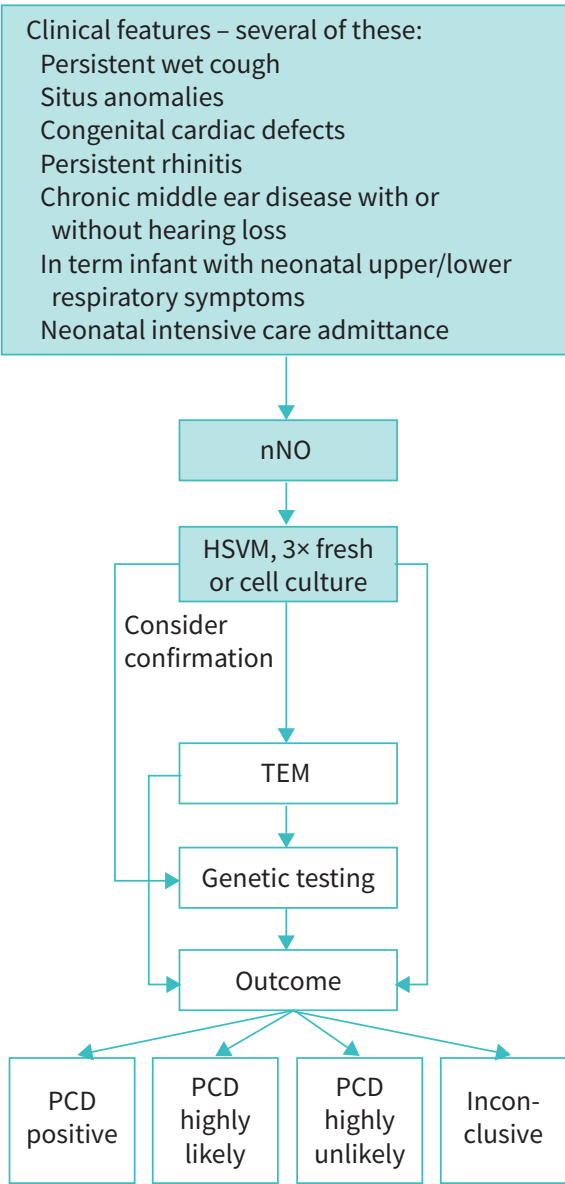

ATS

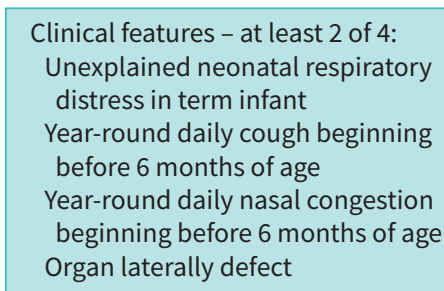

Clinical features - at least 2 of 4 :

nexplained neonatal respiratory

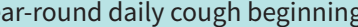

Organ laterally defect
PCD-UNiBe

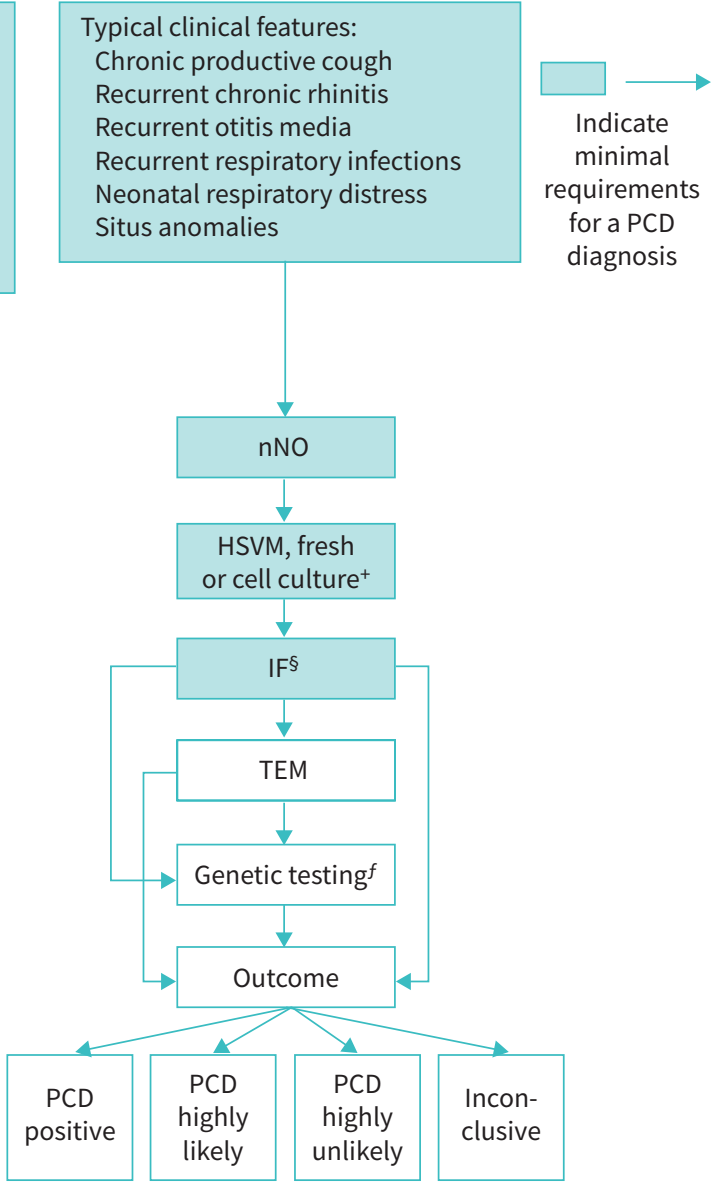

FIGURE 1 Comparison of the three algorithms for PCD diagnosis. Adapted from the ERS [5] and the ATS [7] guidelines. Boxes and arrows marked in blue indicate minimal requirements for a diagnosis. " $\mathrm{nNO}$ can only be used if performed with a chemiluminescence device according to a standard protocol, provided the tested person is $>5$ years old and able to cooperate. A low nNO level should be repeated to ensure the low value is not due to a respiratory infection [7]. "Testing for mutations in $>12$ disease-associated PCD genes, including deletion/duplication [7]. ${ }^{+}$Cell culture at the air-liquid interface (ALI). ${ }^{\S}$ Further investigations (HSVM, immunofluorescence and TEM) are always preferably done by analysing the material of the ALI cell culture. Fresh material is only used if the cell culture is not successful. ${ }^{f}$ Genetic analysis is performed according to newest research findings and the number of tested genes increases constantly. ATS: American Thoracic Society; ERS: European Respiratory Society; HSVM: high-speed videomicroscopy; IF: immunofluorescence staining; nNO: nasal nitric oxide; PCD: primary ciliary dyskinesia; PCD-UNIBE: comprehensive diagnostic centre at the University Children's Hospital, Inselspital Bern, Switzerland; TEM: transmission electron microscopy.

\section{Diagnostic methods}

Nasal nitric oxide ( $\mathrm{nNO}$ ) measurement

nNO is measured according to international standards [17] using the Analyzer CLD 88 sp (Eco Medics, Duernten, Switzerland). It is considered low for children older than 5 years if $<77 \mathrm{~nL} \cdot \mathrm{min}^{-1}$ ( $<233 \mathrm{ppb}$ for our setting) [18-20].

\section{Nasal brushing and further use of the nasal epithelial cells}

We obtain nasal epithelial cells by performing minimal invasive nasal brushings using interdental brushes (IDB-G50 $3 \mathrm{~mm}$, Top Caredent, Zurich, Switzerland; elongated by attaching a $200-\mu \mathrm{L}$ pipette tip with parafilm). Cells are washed down from the brushes and used for further investigations as described below.

High-speed videomicroscopy

Epithelial cells of fresh brushings and of ALI cell cultures are recorded in sealed imaging chambers (Grace Bio-Labs CoverWell ${ }^{\mathrm{TM}}$, GBL635051-40EA, Sigma-Aldrich, Buchs, Switzerland) on an inverted transmitted light microscope (Olympus IX73) equipped with a high-speed C-MOS camera (FLIR 3.2 MP Mono Grasshopper3 USB 3.0 Camera, Sony IMX252 chip). We usually record 10 fields of view (side 


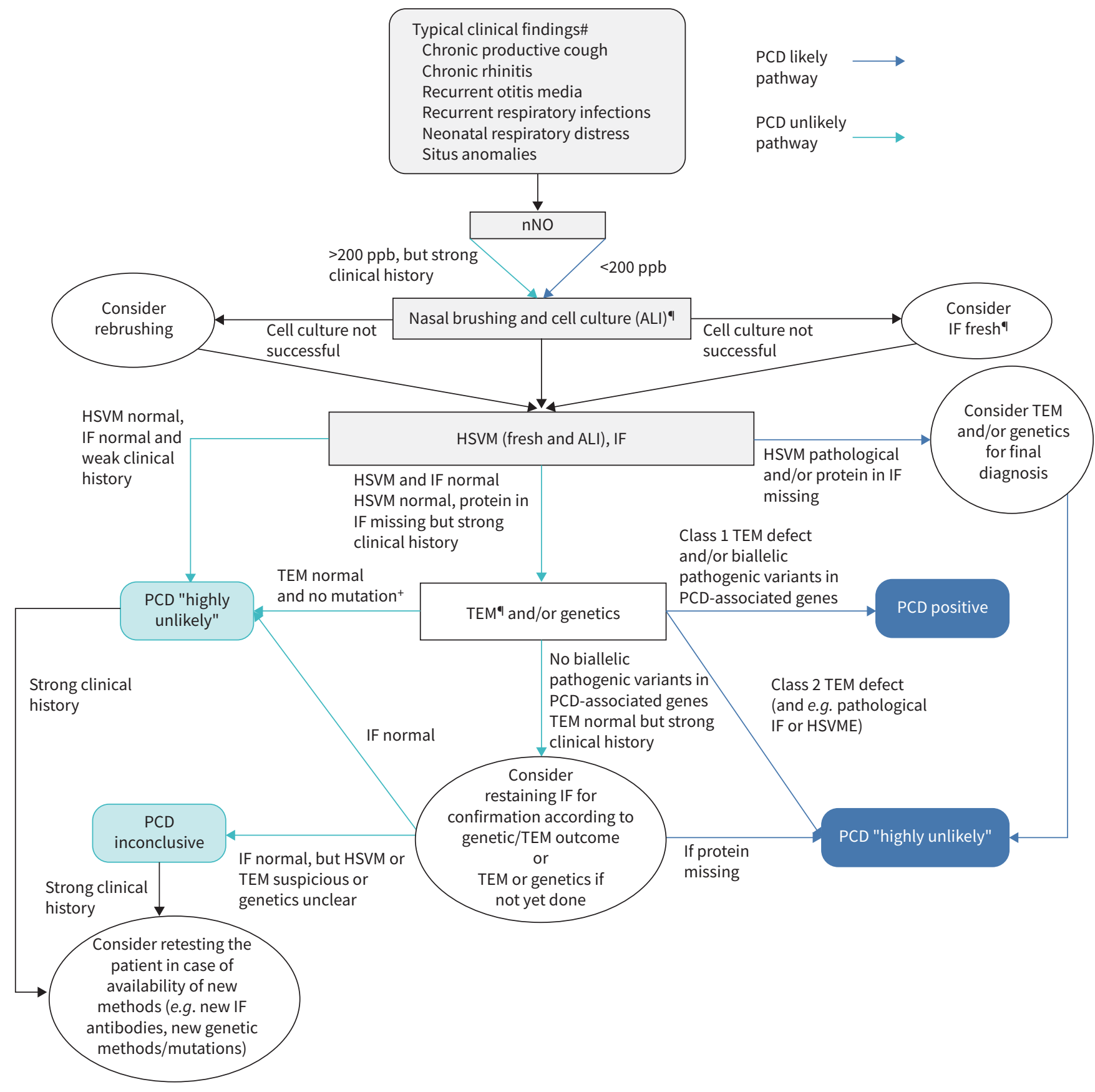

FIGURE 2 Diagnostic algorithm of the PCD-UNIBE diagnostic centre at the University Children's Hospital, Inselspital Bern, Switzerland. Explanation of figures: rectangular boxes: investigations, oval boxes: decisions/considerations, round-edged rectangular boxes: results/outcome. The grey boxes indicate basic methods which are used for each patient being referred to PCD-UNIBE for PCD diagnostics. \#As a clinical screening, the PICADAR-Score [16] may be useful. "Further investigations (HSVM, IF and TEM) are always preferably done using material obtained from ALI cell cultures. Consider rebrushing if cell culture is not successful (especially for TEM); if rebrushing is not possible, fresh material is used. ${ }^{+}$If other results suggest PCD, we recommend further investigations, e.g. RNA analysis or array-based comparative genomic hybridisation (array-CGH). ALI: air-liquid interface; HSVM: high-speed videomicroscopy; IF: immunofluorescence staining; nNO: nasal nitric oxide; PCD: primary ciliary dyskinesia; PCD-UNIBE: comprehensive diagnostic centre at the University Children's Hospital, Inselspital Bern, Switzerland; TEM: transmission electron microscopy.

views and at least one top view) (bright field, 40× magnification, 300 frames per second, 640×480 pixels, $2 \mathrm{~s})$ at room temperature $\left(23-25^{\circ} \mathrm{C}\right)$. Ciliary beating pattern (CBP), beating amplitude, intracellular and intercellular beating coordination, and ciliary beating frequency are analysed based on previously proposed criteria [21, 22]. 
Immunofluorescence staining

Immunofluorescence stainings are performed following a procedure derived from published protocols [13, 14, 23]. Our standard panel includes the staining for DNAH5, GAS8 and RSPH9 proteins. Upon suspicion of incomplete DNAH5 staining, we also stain for DNAH9 and DNAH11. In case of a specific CBP in the HSVM, we stain for other proteins (e.g. RSPH1, RSPH4a and RSPH3 in case of rotating cilia, DNAH11 in case of stiff beating with reduced amplitude or DNAH9 in case of distal stiffness). We cannot cover all relevant proteins, but our standard panel includes the proteins affected by the most prevalent mutations $[13,24]$. For details of the staining protocols (including all available proteins), see supplementary material.

Transmission electron microscopy

Samples are processed according to standard protocols (see supplementary material for details). TEM analysis and reporting follows the BEAT-PCD TEM criteria [12] with additional discrimination between proximal and distal localisation.

ALI cell culture

Nasal epithelial cells of all patients are cultured using the PneumaCult media (Stemcell Technologies, Saint-Egrève, France) following the manufacturer's instruction with some adaptations partially published previously [15] (for details see supplementary material).

\section{Genetic analysis}

For genetic analysis patients’ blood samples (collected in EDTA tubes) were sent to genetic testing centres (Molecular and Genetic Diagnostic Lab, University Hospital Geneva or Human Genetics, Inselspital, Bern University Hospital, Switzerland) to check for genetic variants in up to 46 PCD-associated genes by whole exome sequencing (next-generation sequencing) (details on tested genes are given in supplementary tables S1 and S3).

\section{Statistics}

We compared the ERS with the ATS algorithm, and both with our own PCD-UNIBE algorithm concerning agreement and concordance on PCD diagnosis. Therefore, we used Cohen's $\kappa$ to assess interrater agreement of the three algorithms [25], and we described concordance for the three algorithms using a Venn diagram [26]. The analyses were done using Stata ${ }^{\mathrm{TM}}$ (Stata Statistical Software: Release 14; StataCorp LP, College Station, TX, USA).

Results

Study population

We included 54 patients referred to our PCD-UNIBE centre from 10 Swiss hospitals between January 2018 and December 2020. For all of them we had sufficient information to define the diagnostic outcome based on all three investigated algorithms. 24 patients (44\%) were diagnosed with PCD based on at least one of the three algorithms (table 1 for concordant cases, table 2 for discordant cases, supplementary table S1 for detailed information of all cases). 30 patients were not diagnosed with PCD according to all three algorithms (supplementary table S3). nNO measurement was performed in 46, HSVM in 54, immunofluorescence in 53, TEM in 30 and genetics in 32 of 54 patients. Supplementary table S4 summarises the performed investigations.

\section{Diagnostic outcome}

We compared the diagnostic outcome between the ERS, the ATS and the PCD-UNIBE algorithms for all patients. Out of 54 patients, 46 had a concordant outcome according to all three algorithms: 16 patients with confirmed PCD (table 1) and 30 patients with excluded PCD (supplementary table S3). We found different outcomes for eight out of the 54 patients (15\%) (table 2). Low nNO levels led to a PCD diagnosis for five patients (patients 15-19) according to the ATS algorithm only. Patient 14 was diagnosed with PCD according to the ERS and the PCD-UNIBE (suggestive HSVM with rotating cilia after cell culture) (Supplementary videos S1 and S2), but not according to the ATS algorithm (normal nNO measurement and non-diagnostic TEM defect, refusing of genetic testing). Patient 9 was diagnosed according to the PCD-UNIBE (missing DNAH9 in immunofluorescence, figure 3) and the ATS (low nNO), but not the ERS algorithm (normal TEM, inconclusive HSVM, non-diagnostic genetics). Lastly, patient 4 was diagnosed according to the PCD-UNIBE (missing DNAH9 in immunofluorescence (figure 3), class 2 TEM defect (figure 4)), but neither according to the ERS nor the ATS algorithm (inconclusive HSVM, non-diagnostic TEM and genetics). 


\begin{tabular}{|c|c|c|c|c|c|c|c|c|c|c|c|c|c|c|}
\hline $\begin{array}{l}\text { Patient } \\
\text { number } \\
\text { (lab ID) }\end{array}$ & $\begin{array}{l}\text { Age at } \\
\text { referral } \\
\text { years }\end{array}$ & Sex & Clinical features & $\begin{array}{l}\mathrm{nNO}^{\#} \\
\mathrm{~nL} \cdot \mathrm{min}^{-19}\end{array}$ & $\begin{array}{l}\text { HSVM fresh (more } \\
\text { details in } \\
\text { supplementary } \\
\text { table S1) }\end{array}$ & $\begin{array}{l}\text { HSVM ALI (more } \\
\text { details in } \\
\text { supplementary } \\
\text { table S1) }\end{array}$ & $\begin{array}{l}\text { IF (more details in } \\
\text { supplementary } \\
\text { table S1) }\end{array}$ & $\begin{array}{l}\text { TEM BEAT-PCD } \\
\text { classification [12] }\end{array}$ & $\begin{array}{c}\text { Genetics } \\
\text { ACMG-classification [27] }\end{array}$ & $\begin{array}{l}\text { Costs } \\
\text { EUR }\end{array}$ & Outcome ATS & $\begin{array}{l}\text { Outcome } \\
\text { ERS }\end{array}$ & $\begin{array}{l}\text { Outcome } \\
\text { PCD-UNIBE }\end{array}$ & $\begin{array}{l}\text { Main tools } \\
\text { leading to } \\
\text { diagnosis }\end{array}$ \\
\hline $1(264)$ & 5.0 & $f$ & $\begin{array}{l}\text { Chronic wet } \\
\text { cough } \\
\text { Recurrent } \\
\text { serous otitis } \\
\text { media } \\
\text { Recurrent } \\
\text { Haemophilus } \\
\text { influenzae } \\
\text { infections } \\
\text { Less symptoms } \\
\text { on antibiotics }\end{array}$ & $214^{9}$ & Inconclusive & $\begin{array}{l}\text { Suspicious for } \\
\text { PCD }\end{array}$ & $\begin{array}{l}\text { DNALI1 missing or } \\
\text { strongly reduced } \\
\text { (ALI) }\end{array}$ & $\begin{array}{l}\text { IDA defect \& } \\
\text { tubular } \\
\text { disorganisation } \\
>50 \% \text { (ALI) } \\
\text { class } 1 \text { defect, } \\
\text { diagnostic for } \\
\text { PCD }\end{array}$ & $\begin{array}{l}\text { No likely pathogenic or } \\
\text { pathogenic variant in } 43 \\
\text { genes tested (2020), } \\
\text { negative }\end{array}$ & 7855 & $\begin{array}{l}\text { PCD diagnosed } \\
\text { hallmark (class } 1 \text { ) } \\
\text { TEM defect }\end{array}$ & $\begin{array}{l}\text { PCD } \\
\text { positive } \\
\text { HSVM } \\
\text { repeatedly } \\
\text { suggestive } \\
\text { hallmark } \\
\text { (class 1) } \\
\text { TEM defect }\end{array}$ & $\begin{array}{l}\text { PCD positive } \\
\text { HSVM } \\
\text { suggestive } \\
\text { class } 1 \text { TEM } \\
\text { defect }\end{array}$ & $\begin{array}{l}\text { Clinics } \\
\text { TEM } \\
\text { cell culture }\end{array}$ \\
\hline $2(290)$ & 17.4 & $f$ & $\begin{array}{c}\text { Recurrent } \\
\text { rhinitis } \\
\text { Rhinopolyps } \\
\text { Recurrent } \\
\text { infections with } \\
\text { Haemophilus } \\
\text { influenza } \\
\text { Serous otitis } \\
\text { media }\end{array}$ & $\begin{array}{c}2 \\
2 \\
0.5 \\
1.6\end{array}$ & $\begin{array}{l}\text { High evidence for } \\
\text { PCD }\end{array}$ & $\begin{array}{l}\text { High evidence for } \\
\text { PCD }\end{array}$ & $\begin{array}{l}\text { DNAH11 } \\
\text { repeatedly } \\
\text { missing (ALI) }\end{array}$ & $\begin{array}{l}\text { Non-diagnostic } \\
\text { (ALI) }\end{array}$ & $\begin{array}{l}\text { Monoallelic DNAH11 } \\
\text { mutation, non-diagnostic, } \\
\text { classified likely pathogenic } \\
\text { (4) if biallelic }\end{array}$ & 6855 & $\begin{array}{l}\text { PCD diagnosed } \\
\text { suggestive clinics } \\
\text { nNO repeatedly } \\
\text { low }\end{array}$ & $\begin{array}{l}\text { PCD highly } \\
\text { likely } \\
\text { nNO } \\
\text { repeatedly } \\
\text { low } \\
\text { HSVM } \\
\text { repeatedly } \\
\text { suggestive }\end{array}$ & $\begin{array}{l}\text { PCD highly } \\
\text { likely } \\
\text { nNO } \\
\text { repeatedly } \\
\text { low } \\
\text { HSVM } \\
\text { suggestive } \\
\text { IF with } \\
\text { DNAH11 } \\
\text { missing }\end{array}$ & $\begin{array}{l}\text { Clinics } \\
\text { low nNO } \\
\text { HSVM } \\
\text { cell culture } \\
\text { IF }\end{array}$ \\
\hline $3(284)$ & 15.0 & $\mathrm{~m}$ & $\begin{array}{l}\text { Situs inversus } \\
\text { totalis } \\
\text { Chronic rhinitis } \\
\text { Chronic wet } \\
\text { cough }\end{array}$ & $\begin{array}{l}40 \\
40\end{array}$ & $\begin{array}{l}\text { High evidence for } \\
\text { PCD }\end{array}$ & $\begin{array}{l}\text { High evidence for } \\
\text { PCD }\end{array}$ & $\begin{array}{l}\text { DNAH11 missing } \\
\text { (ALI) }\end{array}$ & $\begin{array}{l}\text { Non-diagnostic } \\
\text { (fresh \& ALI) }\end{array}$ & $\begin{array}{l}\text { Biallelic DNAH11 mutation, } \\
\text { non-diagnostic, classified } \\
\text { unknown significance (3) }\end{array}$ & 7855 & $\begin{array}{l}\text { PCD diagnosed } \\
\text { suggestive clinics } \\
\text { nNO repeatedly } \\
\text { low }\end{array}$ & $\begin{array}{l}\text { PCD highly } \\
\text { likely } \\
\text { nNO } \\
\text { repeatedly } \\
\text { low } \\
\text { HSVM } \\
\text { repeatedly } \\
\text { suggestive }\end{array}$ & $\begin{array}{l}\text { PCD highly } \\
\text { likely } \\
\text { HSVM } \\
\text { suggestive } \\
\text { IF with } \\
\text { DNAH11 } \\
\text { missing }\end{array}$ & $\begin{array}{l}\text { Clinics } \\
\text { HSVM } \\
\text { cell culture } \\
\text { IF }\end{array}$ \\
\hline $5(266)$ & 15.0 & $\mathrm{~m}$ & $\begin{array}{c}\text { Serous otitis } \\
\text { media } \\
\text { Chronic rhinitis } \\
\text { Recurrent low } \\
\text { nNO }\end{array}$ & $\begin{array}{c}21 \\
6 \\
10 \\
9.5^{+}\end{array}$ & $\begin{array}{l}\text { High evidence for } \\
\text { PCD }\end{array}$ & $\begin{array}{l}\text { High evidence for } \\
\text { PCD }\end{array}$ & $\begin{array}{l}\text { DNAH11 missing } \\
\text { (ALI) }\end{array}$ & $\begin{array}{l}\text { Non-diagnostic } \\
\text { (fresh \& ALI) }\end{array}$ & $\begin{array}{c}\text { Biallelic DNAH11 } \\
\text { mutation, compound } \\
\text { heterozygous, diagnostic, } \\
\text { classified pathogenic (5) \& } \\
\text { likely pathogenic (4) }\end{array}$ & 7908 & $\begin{array}{c}\text { PCD diagnosed } \\
\text { suggestive clinics } \\
\text { nNO repeatedly } \\
\text { low } \\
\text { genetics }\end{array}$ & $\begin{array}{l}\text { PCD highly } \\
\text { likely } \\
\text { nNO } \\
\text { repeatedly } \\
\text { low } \\
\text { HSVM } \\
\text { repeatedly } \\
\text { suggestive } \\
\text { genetics }\end{array}$ & $\begin{array}{l}\text { PCD highly } \\
\text { likely } \\
\text { HSVM } \\
\text { suggestive } \\
\text { IF with } \\
\text { DNAH11 } \\
\text { missing } \\
\text { genetics }\end{array}$ & $\begin{array}{l}\text { Clinics } \\
\text { low nNO } \\
\text { HSVM } \\
\text { cell culture } \\
\text { IF } \\
\text { genetics }\end{array}$ \\
\hline
\end{tabular}




\begin{tabular}{|c|c|c|c|c|c|c|c|c|c|c|c|c|c|c|}
\hline $\begin{array}{l}\text { Patient } \\
\text { number } \\
\text { (lab ID) }\end{array}$ & $\begin{array}{l}\text { Age at } \\
\text { referral } \\
\text { years }\end{array}$ & Sex & Clinical features & $\begin{array}{c}\mathrm{nNO}^{\#} \\
\mathrm{~nL} \cdot \mathrm{min}^{-19}\end{array}$ & $\begin{array}{l}\text { HSVM fresh (more } \\
\text { details in } \\
\text { supplementary } \\
\text { table S1) }\end{array}$ & $\begin{array}{l}\text { HSVM ALI (more } \\
\text { details in } \\
\text { supplementary } \\
\text { table S1) }\end{array}$ & $\begin{array}{l}\text { IF (more details in } \\
\text { supplementary } \\
\text { table } \mathrm{S} 1 \text { ) }\end{array}$ & $\begin{array}{l}\text { TEM BEAT-PCD } \\
\text { classification [12] }\end{array}$ & $\begin{array}{c}\text { Genetics } \\
\text { ACMG-classification [27] }\end{array}$ & $\begin{array}{l}\text { Costs } \\
\text { EUR }\end{array}$ & Outcome ATS & $\begin{array}{l}\text { Outcome } \\
\text { ERS }\end{array}$ & $\begin{array}{l}\text { Outcome } \\
\text { PCD-UNIBE }\end{array}$ & $\begin{array}{l}\text { Main tools } \\
\text { leading to } \\
\text { diagnosis }\end{array}$ \\
\hline $6(267)$ & 1.4 & $\mathrm{~m}$ & $\begin{array}{l}\text { Situs inversus } \\
\text { totalis } \\
\text { Chronic rhinitis }\end{array}$ & $4.5^{9,+,+,, f}$ & Inconclusive & $\begin{array}{l}\text { High evidence for } \\
\text { PCD }\end{array}$ & $\begin{array}{l}\text { DNAH11 missing } \\
\text { (fresh) }\end{array}$ & Non-diagnostic & $\begin{array}{c}\text { Biallelic DNAH11 } \\
\text { mutation, diagnostic, } \\
\text { classified pathogenic (5) }\end{array}$ & 5855 & $\begin{array}{l}\text { PCD diagnosed } \\
\text { (nNO low) } \\
\text { confirmed } \\
\text { genetics }\end{array}$ & $\begin{array}{l}\text { PCD } \\
\text { positive } \\
\text { HSVM } \\
\text { suggestive } \\
\text { confirmed } \\
\text { genetics }\end{array}$ & $\begin{array}{l}\text { PCD positive } \\
\text { HSVM } \\
\text { suggestive } \\
\text { IF with } \\
\text { DNAH11 } \\
\text { missing } \\
\text { confirmed } \\
\text { genetics }\end{array}$ & $\begin{array}{l}\text { Clinics } \\
\text { HSVM } \\
\text { cell culture } \\
\text { IF } \\
\text { genetics }\end{array}$ \\
\hline 7 (298) & 2.8 & $\mathrm{~m}$ & $\begin{array}{l}\text { Situs inversus } \\
\text { totalis } \\
\text { NRDS } \\
\text { Nasal secretion } \\
\text { Productive } \\
\text { cough }\end{array}$ & $\begin{array}{c}5 \\
29.5^{4,+}\end{array}$ & PCD likely & $\begin{array}{l}\text { Cell culture not } \\
\text { successful }\end{array}$ & Inconclusive & - & $\begin{array}{l}\text { Biallelic DNAH5 mutation, } \\
\text { diagnostic, classified } \\
\text { pathogenic (5) }\end{array}$ & 3925 & $\begin{array}{l}\text { PCD diagnosed } \\
\text { nNO } \\
\text { repeatedlylow" } \\
\text { confirmed } \\
\text { genetics }\end{array}$ & $\begin{array}{l}\text { PCD } \\
\text { positive } \\
\text { HSVM } \\
\text { suggestive } \\
\text { confirmed } \\
\text { genetics }\end{array}$ & $\begin{array}{l}\text { PCD positive } \\
\text { HSVM } \\
\text { suggestive } \\
\text { confirmed } \\
\text { genetics }\end{array}$ & $\begin{array}{l}\text { Clinics } \\
\text { genetics }\end{array}$ \\
\hline $8(318)$ & 16.9 & f & $\begin{array}{l}\text { Situs inversus } \\
\text { totalis } \\
\text { Chronic wet } \\
\text { cough }\end{array}$ & $\begin{array}{l}205 \\
163\end{array}$ & PCD likely & $\begin{array}{l}\text { High evidence for } \\
\text { PCD }\end{array}$ & $\begin{array}{l}\text { DNAH11 missing } \\
\text { (ALI) }\end{array}$ & - & $\begin{array}{c}\text { Biallelic DNAH11 } \\
\text { mutation, diagnostic, } \\
\text { classified pathogenic (5) \& } \\
\text { likely pathogenic (4) }\end{array}$ & 4855 & $\begin{array}{l}\text { PCD diagnosed } \\
\text { suggestive clinics } \\
\text { confirmed } \\
\text { genetics }\end{array}$ & $\begin{array}{l}\text { PCD } \\
\text { positive } \\
\text { suggestive } \\
\text { clinics } \\
\text { HSVM } \\
\text { repeatedly } \\
\text { suggestive } \\
\text { confirmed } \\
\text { genetics }\end{array}$ & $\begin{array}{l}\text { PCD positive } \\
\text { suggestive } \\
\text { clinics } \\
\text { HSVM } \\
\text { pathological } \\
\text { IF with } \\
\text { DNAH11 } \\
\text { missing } \\
\text { confirmed } \\
\text { genetics }\end{array}$ & $\begin{array}{l}\text { Clinics } \\
\text { IF } \\
\text { cell culture } \\
\text { genetics }\end{array}$ \\
\hline $10(338)$ & 14.1 & $f$ & $\begin{array}{c}\text { Chronic } \\
\text { purulent cough } \\
\text { Chronic rhinitis } \\
\text { obstructive \& } \\
\text { restrictive } \\
\text { ventilation } \\
\text { disorder } \\
\text { NRDS } \\
\text { Positive family } \\
\text { history } \\
\text { (mother 11, } \\
\text { brother 12) }\end{array}$ & $7^{+, \text {s }}$ & $\begin{array}{l}\text { High evidence for } \\
\text { PCD }\end{array}$ & $\begin{array}{l}\text { High evidence for } \\
\text { PCD }\end{array}$ & $\begin{array}{l}\text { DNAH5 } \\
\text { completely } \\
\text { missing (fresh } \\
\text { and ALI) }\end{array}$ & $\begin{array}{c}\text { ODA \& IDA } \\
\text { missing }>50 \% \\
\text { (ALI) } \\
\text { class 1 defect, } \\
\text { diagnostic for } \\
\text { PCD }\end{array}$ & - & 2877 & $\begin{array}{l}\text { PCD diagnosed } \\
\text { nNO low } \\
\text { hallmark (class 1) } \\
\text { TEM defect }\end{array}$ & $\begin{array}{c}\text { PCD } \\
\text { positive } \\
\text { nNO low } \\
\text { HSVM } \\
\text { repeatedly } \\
\text { suggestive } \\
\text { hallmark } \\
\text { (class 1) } \\
\text { TEM defect }\end{array}$ & $\begin{array}{l}\text { PCD positive } \\
\text { HSVM } \\
\text { suggestive } \\
\text { class } 1 \text { TEM } \\
\text { defect } \\
\text { IF with } \\
\text { DNAH5 } \\
\text { missing }\end{array}$ & $\begin{array}{l}\text { HSVM } \\
\text { cell culture } \\
\text { IF } \\
\text { TEM }\end{array}$ \\
\hline 11 (339) & 42.4 & $f$ & $\begin{array}{l}\text { Chronic } \\
\text { purulent cough } \\
\text { Situs inversus } \\
\text { totalis } \\
\text { Bronchiectasis } \\
\text { (mother of } \\
\text { patients } 10 \text { \& } \\
\text { 12) }\end{array}$ & - & Inconclusive & $\begin{array}{l}\text { High evidence for } \\
\text { PCD }\end{array}$ & $\begin{array}{l}\text { DNAH5 } \\
\text { completely } \\
\text { missing (fresh } \\
\text { and ALI) }\end{array}$ & $\begin{array}{c}\text { ODA \& IDA } \\
\text { missing > } 50 \% \\
\text { (ALI) } \\
\text { class } 1 \text { defect, } \\
\text { diagnostic for } \\
\text { PCD }\end{array}$ & - & 2802 & $\begin{array}{l}\text { PCD diagnosed } \\
\text { hallmark (class 1) } \\
\text { TEM defect }\end{array}$ & $\begin{array}{c}\text { PCD } \\
\text { positive } \\
\text { HSVM } \\
\text { repeatedly } \\
\text { suggestive } \\
\text { hallmark } \\
\text { (class 1) } \\
\text { TEM defect }\end{array}$ & $\begin{array}{l}\text { PCD positive } \\
\text { HSVM } \\
\text { suggestive } \\
\text { class } 1 \text { TEM } \\
\text { defect } \\
\text { IF with } \\
\text { DNAH5 } \\
\text { missing }\end{array}$ & $\begin{array}{c}\text { HSVM } \\
\text { cell culture } \\
\text { IF } \\
\text { TEM }\end{array}$ \\
\hline
\end{tabular}




\begin{tabular}{|c|c|c|c|c|c|c|c|c|c|c|c|c|c|c|}
\hline $\begin{array}{l}\text { Patient } \\
\text { number } \\
\text { (lab ID) }\end{array}$ & $\begin{array}{l}\text { Age at } \\
\text { referral } \\
\text { years }\end{array}$ & Sex & Clinical features & $\begin{array}{c}\mathrm{nNO}^{\#} \\
\mathrm{~nL} \cdot \mathrm{min}^{-19}\end{array}$ & $\begin{array}{l}\text { HSVM fresh (more } \\
\text { details in } \\
\text { supplementary } \\
\text { table S1) }\end{array}$ & $\begin{array}{l}\text { HSVM ALI (more } \\
\text { details in } \\
\text { supplementary } \\
\text { table S1) }\end{array}$ & $\begin{array}{l}\text { IF (more details in } \\
\text { supplementary } \\
\text { table } \mathrm{S} 1 \text { ) }\end{array}$ & $\begin{array}{l}\text { TEM BEAT-PCD } \\
\text { classification [12] }\end{array}$ & $\begin{array}{l}\text { Genetics } \\
\text { ACMG-classification [27] }\end{array}$ & $\begin{array}{l}\text { Costs }{ }^{9 \varphi} \\
\text { EUR }\end{array}$ & Outcome ATS & $\begin{array}{l}\text { Outcome } \\
\text { ERS }\end{array}$ & $\begin{array}{l}\text { Outcome } \\
\text { PCD-UNIBE }\end{array}$ & $\begin{array}{l}\text { Main tools } \\
\text { leading to } \\
\text { diagnosis }\end{array}$ \\
\hline $12(354)$ & 9.6 & $\mathrm{~m}$ & $\begin{array}{c}\text { Chronic } \\
\text { purulent cough } \\
\text { Chronic rhinitis } \\
\text { Positive family } \\
\text { history } \\
\text { (mother 11, } \\
\text { sister 10) }\end{array}$ & $7^{+, 5}$ & $\begin{array}{l}\text { High evidence for } \\
\text { PCD }\end{array}$ & $\begin{array}{l}\text { Cell culture not } \\
\text { successful }\end{array}$ & Inconclusive & $\begin{array}{c}\text { ODA \& IDA } \\
\text { missing }>50 \% \\
\text { (fresh) } \\
\text { class } 1 \text { defect, } \\
\text { diagnostic for } \\
\text { PCD }\end{array}$ & - & 2925 & $\begin{array}{l}\text { PCD diagnosed } \\
\text { nNO low } \\
\text { hallmark (class 1) } \\
\text { TEM defect }\end{array}$ & $\begin{array}{l}\text { PCD } \\
\text { positive } \\
\text { nNO low } \\
\text { HSVM } \\
\text { repeatedly } \\
\text { suggestive } \\
\text { hallmark } \\
\text { (class 1) } \\
\text { TEM defect }\end{array}$ & $\begin{array}{l}\text { PCD positive } \\
\text { HSVM } \\
\text { suggestive } \\
\text { class } 1 \text { TEM } \\
\text { defect }\end{array}$ & $\begin{array}{l}\text { HSVM } \\
\text { TEM }\end{array}$ \\
\hline $13(343)$ & 17.4 & $\mathrm{~m}$ & $\begin{array}{l}\text { Chronic wet } \\
\text { cough } \\
\text { Chronic rhinitis } \\
\text { and } \\
\text { nasal } \\
\text { obstruction } \\
\text { Positive family } \\
\text { history }\end{array}$ & $\begin{array}{c}5 \\
9 \\
2^{+}\end{array}$ & PCD likely & PCD likely & $\begin{array}{l}\text { All proteins } \\
\text { present }^{\# \#}\end{array}$ & - & $\begin{array}{l}\text { Biallelic HYDIN mutation, } \\
\text { diagnostic, classified } \\
\text { pathogenic (5) }\end{array}$ & 4855 & $\begin{array}{l}\text { PCD diagnosed } \\
\text { nNO repeatedly } \\
\text { low } \\
\text { confirmed } \\
\text { genetics }\end{array}$ & $\begin{array}{c}\text { PCD } \\
\text { positive } \\
\text { nNO low } \\
\text { HSVM } \\
\text { repeatedly } \\
\text { suggestive } \\
\text { confirmed } \\
\text { genetics }\end{array}$ & $\begin{array}{l}\text { PCD positive } \\
\text { nNO low } \\
\text { HSVM } \\
\text { suggestive } \\
\text { confirmed } \\
\text { genetics }\end{array}$ & $\begin{array}{l}\text { Clinics } \\
\text { nNO } \\
\text { genetics }\end{array}$ \\
\hline $20(346)$ & 66.0 & $f$ & $\begin{array}{l}\text { Situs inversus } \\
\text { totalis } \\
\text { Positive family } \\
\text { history (sister of } \\
21,22 \& 23 \text { ) } \\
\text { Chronic rhinitis } \\
\text { Chronic wet } \\
\text { cough } \\
\text { Nasal polyposis } \\
\text { Recurrent } \\
\text { sinusitis } \\
\text { Bronchiectasis } \\
\text { Shortness of } \\
\text { breath }\end{array}$ & $9^{+, \S}$ & $\begin{array}{l}\text { High evidence for } \\
\text { PCD }\end{array}$ & $\begin{array}{l}\text { High evidence for } \\
\text { PCD }\end{array}$ & $\begin{array}{l}\text { DNAH11 missing } \\
\text { (ALI) }\end{array}$ & Non-diagnostic & $\begin{array}{l}\text { Biallelic DNAH11 } \\
\text { mutation, diagnostic, } \\
\text { classified likely pathogenic } \\
\text { (4) }\end{array}$ & 5855 & $\begin{array}{l}\text { PCD diagnosed } \\
\text { suggestive clinics } \\
\text { nNO low } \\
\text { confirmed } \\
\text { genetics }\end{array}$ & $\begin{array}{l}\text { PCD } \\
\text { positive } \\
\text { nNO low } \\
\text { HSVM } \\
\text { repeatedly } \\
\text { suggestive } \\
\text { confirmed } \\
\text { genetics }\end{array}$ & $\begin{array}{l}\text { PCD positive } \\
\text { nNO low } \\
\text { HSVM } \\
\text { suggestive } \\
\text { IF with } \\
\text { DNAH11 } \\
\text { missing } \\
\text { confirmed } \\
\text { genetics }\end{array}$ & $\begin{array}{c}\text { HSVM } \\
\text { cell culture } \\
\text { IF } \\
\text { genetics }\end{array}$ \\
\hline $21(347)$ & 65.0 & $f$ & $\begin{array}{l}\text { Positive family } \\
\text { history (sister of } \\
20,22 \& 23 \text { ) } \\
\text { Chronic rhinitis } \\
\text { Chronic cough } \\
\text { Subfertility }\end{array}$ & $9^{+, \S}$ & $\begin{array}{l}\text { High evidence for } \\
\text { PCD }\end{array}$ & $\begin{array}{l}\text { High evidence for } \\
\text { PCD }\end{array}$ & $\begin{array}{l}\text { DNAH11 missing } \\
\text { (ALI) }\end{array}$ & $\begin{array}{l}\text { Non-diagnostic } \\
\text { (ALI) }\end{array}$ & $\begin{array}{c}\text { Biallelic DNAH11 } \\
\text { mutation, diagnostic, } \\
\text { classified likely pathogenic } \\
\text { (4) }\end{array}$ & 5855 & $\begin{array}{l}\text { PCD diagnosed } \\
\text { suggestive clinics } \\
\text { nNO low } \\
\text { confirmed } \\
\text { genetics }\end{array}$ & $\begin{array}{c}\text { PCD } \\
\text { positive } \\
\text { nNO low } \\
\text { HSVM } \\
\text { repeatedly } \\
\text { suggestive } \\
\text { confirmed } \\
\text { genetics }\end{array}$ & $\begin{array}{l}\text { PCD positive } \\
\text { nNO low } \\
\text { HSVM } \\
\text { suggestive } \\
\text { IF with } \\
\text { DNAH11 } \\
\text { missing } \\
\text { confirmed } \\
\text { genetics }\end{array}$ & $\begin{array}{c}\text { HSVM } \\
\text { cell culture } \\
\text { IF } \\
\text { genetics }\end{array}$ \\
\hline
\end{tabular}




\begin{tabular}{|c|c|c|c|c|c|c|c|c|c|c|c|c|c|c|}
\hline $\begin{array}{l}\text { Patient } \\
\text { number } \\
\text { (lab ID) }\end{array}$ & $\begin{array}{l}\text { Age at } \\
\text { referral } \\
\text { years }\end{array}$ & Sex & Clinical features & $\begin{array}{c}\mathrm{nNO}^{\#} \\
\mathrm{~nL} \cdot \mathrm{min}^{-19}\end{array}$ & $\begin{array}{l}\text { HSVM fresh (more } \\
\text { details in } \\
\text { supplementary } \\
\text { table S1) }\end{array}$ & $\begin{array}{l}\text { HSVM ALI (more } \\
\text { details in } \\
\text { supplementary } \\
\text { table S1) }\end{array}$ & $\begin{array}{l}\text { IF (more details in } \\
\text { supplementary } \\
\text { table S1) }\end{array}$ & $\begin{array}{l}\text { TEM BEAT-PCD } \\
\text { classification [12] }\end{array}$ & $\begin{array}{l}\text { Genetics } \\
\text { ACMG-classification [27] }\end{array}$ & $\begin{array}{l}\text { Costs }^{4 \uparrow} \\
\text { EUR }\end{array}$ & Outcome ATS & $\begin{array}{l}\text { Outcome } \\
\text { ERS }\end{array}$ & $\begin{array}{l}\text { Outcome } \\
\text { PCD-UNIBE }\end{array}$ & $\begin{array}{c}\text { Main tools } \\
\text { leading to } \\
\text { diagnosis }\end{array}$ \\
\hline $22(348)$ & 67.8 & $\mathrm{~m}$ & $\begin{array}{l}\text { Positive family } \\
\text { history (sister of } \\
20,21 \& 23 \text { ) } \\
\text { Chronic wet } \\
\text { cough } \\
\text { Nasal polyposis } \\
\text { Chronic rhinitis }\end{array}$ & $1^{+, 5}$ & $\begin{array}{l}\text { High evidence for } \\
\text { PCD }\end{array}$ & $\begin{array}{l}\text { High evidence for } \\
\text { PCD }\end{array}$ & $\begin{array}{l}\text { DNAH11 missing } \\
\text { (ALI) }\end{array}$ & $\begin{array}{l}\text { Non-diagnostic } \\
\text { (ALI) }\end{array}$ & $\begin{array}{l}\text { Biallelic DNAH11 } \\
\text { mutation, diagnostic, } \\
\text { classified likely pathogenic } \\
\text { (4) }\end{array}$ & 5855 & $\begin{array}{l}\text { PCD diagnosed } \\
\text { suggestive clinics } \\
\text { nNO low } \\
\text { confirmed } \\
\text { genetics }\end{array}$ & $\begin{array}{c}\text { PCD } \\
\text { positive } \\
\text { nNO low } \\
\text { HSVM } \\
\text { repeatedly } \\
\text { suggestive } \\
\text { confirmed } \\
\text { genetics }\end{array}$ & $\begin{array}{l}\text { PCD positive } \\
\text { nNO low } \\
\text { HSVM } \\
\text { suggestive } \\
\text { IF with } \\
\text { DNAH11 } \\
\text { missing } \\
\text { confirmed } \\
\text { genetics }\end{array}$ & $\begin{array}{c}\text { HSVM } \\
\text { cell culture } \\
\text { IF } \\
\text { genetics }\end{array}$ \\
\hline $23(349)$ & 68.9 & $\mathrm{f}$ & $\begin{array}{l}\text { Positive family } \\
\text { history (sister of } \\
20,21 \text { \& 22) } \\
\text { Chronic rhinitis } \\
\text { Chronic wet } \\
\text { cough }\end{array}$ & $5.5^{5^{, 5}}$ & $\begin{array}{l}\text { High evidence for } \\
\text { PCD }\end{array}$ & $\begin{array}{l}\text { High evidence for } \\
\text { PCD }\end{array}$ & $\begin{array}{l}\text { DNAH11 missing } \\
\text { (ALI) }\end{array}$ & $\begin{array}{l}\text { Non-diagnostic } \\
\text { (ALI) }\end{array}$ & $\begin{array}{c}\text { Biallelic DNAH11 } \\
\text { mutation, diagnostic, } \\
\text { classified likely pathogenic } \\
\text { (4) }\end{array}$ & 5855 & $\begin{array}{l}\text { PCD diagnosed } \\
\text { suggestive clinics } \\
\text { nNO low } \\
\text { confirmed } \\
\text { genetics }\end{array}$ & $\begin{array}{c}\text { PCD } \\
\text { positive } \\
\text { nNO low } \\
\text { HSVM } \\
\text { repeatedly } \\
\text { suggestive } \\
\text { confirmed } \\
\text { genetics }\end{array}$ & $\begin{array}{l}\text { PCD positive } \\
\text { nNO low } \\
\text { HSVM } \\
\text { suggestive } \\
\text { IF with } \\
\text { DNAH11 } \\
\text { missing } \\
\text { confirmed } \\
\text { genetics }\end{array}$ & $\begin{array}{c}\text { HSVM } \\
\text { cell culture } \\
\text { IF } \\
\text { genetics }\end{array}$ \\
\hline $24(359)$ & 0.1 & f & $\begin{array}{l}\text { Situs inversus } \\
\text { totalis } \\
\text { NRDS } \\
\text { Chronic nasal } \\
\text { secretion } \\
\text { Chronic } \\
\text { productive } \\
\text { cough }\end{array}$ & $<1^{+, \varsigma, \square}$ & $\begin{array}{l}\text { High evidence for } \\
\text { PCD }\end{array}$ & $\begin{array}{l}\text { High evidence for } \\
\text { PCD }\end{array}$ & $\begin{array}{l}\text { DNAH5, DNAH9, } \\
\text { DNAH11, DNAI1, } \\
\text { DNAI2 missing } \\
\text { (ALI) }\end{array}$ & & $\begin{array}{l}\text { Not yet performed, brother } \\
\text { with diagnostic, biallelic } \\
\text { DNAH5-mutation }\end{array}$ & 2014 & $\begin{array}{l}\text { PCD diagnosed } \\
\text { suggestive clinics } \\
\text { (nNO low) } \\
\text { genetics unclear } \\
\text { (brother with } \\
\text { confirmed } \\
\text { mutation) }\end{array}$ & $\begin{array}{l}\text { PCD highly } \\
\text { likely } \\
\text { HSVM } \\
\text { suggestive }\end{array}$ & $\begin{array}{l}\text { PCD highly } \\
\text { likely } \\
\text { HSVM } \\
\text { suggestive } \\
\text { IF with } \\
\text { proteins } \\
\text { missing }\end{array}$ & $\begin{array}{c}\text { HSVM } \\
\text { cell culture } \\
\text { IF } \\
\text { (genetics) }\end{array}$ \\
\hline
\end{tabular}

Bold text indicates results leading to a diagnosis of PCD and the final diagnosis. ACMG: American College of Medical Genetics and Genomics; ALI: air-liquid interface; ATS: American Thoracic Society; Array-CGH: array-based comparative genomic hybridisation; ERS: European Respiratory Society; f: female; HSVM: high-speed videomicroscopy; IDA: inner dynein arm; IF: immunofluorescence labelling; m: male; nNO: nasal nitric oxide; NRDS: neonatal respiratory distress syndrome; ODA: outer dynein arm; PCD: primary ciliary dyskinesia; PCD-UNIBE: comprehensive diagnostic centre at the University Children's Hospital, Inselspital Bern, Switzerland; TEM: transmission electron microscopy. ${ }^{\#}$ These are mean values for nNO for the right and left side. The unit for $\mathrm{nNO}$ results at our centre is parts per billion ( $\mathrm{ppb})$. To obtain values in $\mathrm{nL} \cdot \mathrm{min}^{-1}$ the formula $(\mathrm{ppb}) \times$ sampling flow rate $\left(0.33 \mathrm{~mL} \cdot \mathrm{min}{ }^{-1}\right.$ for Ecomedics Analyzer CLD $\left.88 \mathrm{sp}\right)$ was used as proposed in LEIGH et al. [18]. ": child $<5$ years old. ${ }^{+}$: cystic fibrosis not excluded by sweat test or genetic testing. ${ }^{\S}$ : single nNO measurement. ${ }^{f}$ : nNO measurement during rhinitis. \#\#: DNAH5, GAS8, RSPH9 and DNAH11 stained. " "थ: remark about the costs: the costs were estimated based on costs that are billed for each method performed (for costs of each method see supplementary table S2 and figure S1). The costs may be higher than in other studies; however, we have to consider that prices and salaries are usually higher in Switzerland compared to other countries. 


\begin{tabular}{|c|c|c|c|c|c|c|c|c|c|c|c|c|c|c|}
\hline $\begin{array}{l}\text { Patient } \\
\text { number } \\
\text { (lab ID) }\end{array}$ & $\begin{array}{l}\text { Age at } \\
\text { referral } \\
\text { years }\end{array}$ & Sex & Clinical features & $\begin{array}{c}\mathrm{nNO} \\
\mathrm{nL} \cdot \mathrm{min}^{-1 \#}\end{array}$ & $\begin{array}{l}\text { HSVM fresh } \\
\text { (more details in } \\
\text { supplementary } \\
\text { table S1) }\end{array}$ & $\begin{array}{l}\text { HSVM ALI (more } \\
\text { details in } \\
\text { supplementary } \\
\text { table S1) }\end{array}$ & IF & $\begin{array}{c}\text { TEM } \\
\text { BEAT-PCD-TEM } \\
{[12]} \\
\text { classification }\end{array}$ & $\begin{array}{c}\text { Genetics } \\
\text { ACMG-classification } \\
{[27]}\end{array}$ & $\begin{array}{l}\text { Costs }^{f} \\
\text { EUR }\end{array}$ & Outcome ATS & Outcome ERS & $\begin{array}{l}\text { Outcome } \\
\text { PCD-UNIBE }\end{array}$ & $\begin{array}{l}\text { Main } \\
\text { tools } \\
\text { leading } \\
\text { to } \\
\text { diagnosis }\end{array}$ \\
\hline $4(272)$ & 6.6 & M & $\begin{array}{l}\text { Bronchiectasis } \\
\text { Chronic wet cough } \\
\text { Sister with similar } \\
\text { symptoms }\end{array}$ & 175 & $\begin{array}{l}\text { No evidence for } \\
\text { PCD }\end{array}$ & $\begin{array}{l}\text { No evidence for } \\
\text { PCD }\end{array}$ & $\begin{array}{c}\text { DNAH9 } \\
\text { missing (ALI) }\end{array}$ & $\begin{array}{c}\text { ODA \& IDA } \\
\text { Defect < <50\% } \\
\text { (ALI) } \\
\text { class } 2 \text { defect, } \\
\text { PCD likely }\end{array}$ & $\begin{array}{l}\text { Two DNAH9 variants } \\
\text { in-cis, non-diagnostic }\end{array}$ & 5908 & $\begin{array}{l}\text { PCD not } \\
\text { diagnosed } \\
\text { nNO normal } \\
\text { Genetics } \\
\text { non-diagnostic } \\
\text { No hallmark } \\
\text { TEM defect }\end{array}$ & $\begin{array}{l}\text { PCD highly } \\
\text { unlikely } \\
\text { No hallmark } \\
\text { TEM defect } \\
\text { Genetics of } \\
\text { unknown } \\
\text { significance }\end{array}$ & $\begin{array}{c}\text { PCD highly } \\
\text { likely } \\
\text { Class } 2 \text { TEM } \\
\text { defect } \\
\text { IF with DNAH9 } \\
\text { missing }\end{array}$ & $\begin{array}{l}\text { Clinics } \\
\text { TEM } \\
\text { cell } \\
\text { culture } \\
\text { IF }\end{array}$ \\
\hline $9(323)$ & 65.1 & M & $\begin{array}{l}\text { Bronchiectasis } \\
\text { Chronic wet cough } \\
\text { Recurrent } \\
\text { respiratory tract } \\
\text { infections }\end{array}$ & $14^{4}$ & $\begin{array}{l}\text { High evidence } \\
\text { for PCD }\end{array}$ & Inconclusive & $\begin{array}{l}\text { DNAH9 } \\
\text { repeatedly } \\
\text { completely } \\
\text { missing (ALI) }\end{array}$ & Non-diagnostic & $\begin{array}{l}\text { No likely pathogenic } \\
\text { or pathogenic variant } \\
\text { found in } 42 \text { genes } \\
\text { tested }(2020)\end{array}$ & 6908 & $\begin{array}{c}\text { PCD } \\
\text { diagnosed } \\
\text { Suggestive } \\
\text { clinics } \\
\text { nNO low } \\
\text { (single } \\
\text { measurement) }\end{array}$ & $\begin{array}{c}\text { PCD highly } \\
\text { unlikely } \\
\text { nNO low } \\
\text { HSVM } \\
\text { inconclusive } \\
\text { TEM } \\
\text { non-diagnostic } \\
\text { Genetics } \\
\text { negative }\end{array}$ & $\begin{array}{l}\text { PCD highly } \\
\text { likely } \\
\text { nNO low } \\
\text { HSVM } \\
\text { inconclusive } \\
\text { IF with DNAH9 } \\
\text { missing }\end{array}$ & $\begin{array}{l}\mathrm{nNO} \\
\text { cell } \\
\text { culture } \\
\text { IF }\end{array}$ \\
\hline $14(361)$ & 23.6 & $\mathrm{~F}$ & $\begin{array}{c}\text { Chronic productive } \\
\text { cough } \\
\text { Chronic rhinitis }\end{array}$ & 152 & Inconclusive & $\begin{array}{l}\text { High evidence } \\
\text { for PCD }\end{array}$ & $\begin{array}{l}\text { All proteins } \\
\text { present }\end{array}$ & $\begin{array}{l}\text { Non-diagnostic } \\
\text { (fresh) }\end{array}$ & Refused by patient & 3855 & $\begin{array}{c}\text { PCD not } \\
\text { diagnosed } \\
\text { nNO normal } \\
\text { TEM } \\
\text { non-diagnostic } \\
\text { (genetics to be } \\
\text { done) }\end{array}$ & $\begin{array}{l}\text { PCD highly } \\
\text { likely } \\
\text { HSVM } \\
\text { repeatedly } \\
\text { suggestive }\end{array}$ & $\begin{array}{l}\text { PCD highly } \\
\text { likely } \\
\text { HSVM } \\
\text { suggestive }\end{array}$ & $\begin{array}{l}\text { HSVM } \\
\text { cell } \\
\text { culture }\end{array}$ \\
\hline $15(253)$ & 9.2 & $\mathrm{~m}$ & $\begin{array}{c}\text { PICADAR } 6 \\
\text { chronic wet cough } \\
\text { Chronic rhinitis } \\
\text { Cardiac } \\
\text { malformation } \\
\text { (pulmonary \& } \\
\text { tricuspid atresia) } \\
\text { Recurrent otitis } \\
\text { media } \\
\text { Immune deficiency }\end{array}$ & $\begin{array}{l}20 \\
9^{+}\end{array}$ & $\begin{array}{l}\text { No evidence for } \\
\text { PCD }\end{array}$ & $\begin{array}{l}\text { No evidence for } \\
\text { PCD }\end{array}$ & $\begin{array}{l}\text { All proteins } \\
\text { present }\end{array}$ & - & & 1908 & $\begin{array}{c}\text { PCD } \\
\text { diagnosed } \\
\text { Suggestive } \\
\text { clinics } \\
\text { nNO } \\
\text { repeatedly low }\end{array}$ & $\begin{array}{l}\text { PCD highly } \\
\text { unlikely } \\
\text { HSVM fresh \& } \\
\text { ALI normal }\end{array}$ & $\begin{array}{l}\text { PCD highly } \\
\text { unlikely } \\
\text { HSVM fresh \& } \\
\text { ALI normal } \\
\text { IF without } \\
\text { protein } \\
\text { missing }\end{array}$ & nNO \\
\hline $16(285)$ & 15.6 & $\mathrm{~m}$ & $\begin{array}{l}\text { Chronic purulent } \\
\text { cough } \\
\text { Chronic rhinitis } \\
\text { Premature birth } \\
\text { Obstructive sleep } \\
\text { apnoea }\end{array}$ & $\begin{array}{c}7.5^{\S} \\
7\end{array}$ & PCD likely & $\begin{array}{l}\text { No evidence for } \\
\text { PCD }\end{array}$ & $\begin{array}{c}\text { DNAH9 } \\
\text { inconclusive } \\
\text { (ALI) } \\
\text { inconclusive }\end{array}$ & $\begin{array}{l}\text { Non-diagnostic } \\
\text { (ALI) }\end{array}$ & $\begin{array}{l}\text { No likely pathogenic } \\
\text { or pathogenic variant } \\
\text { found in } 43 \text { genes } \\
\text { tested ( } 2020)\end{array}$ & 6249 & $\begin{array}{c}\text { PCD } \\
\text { diagnosed } \\
\text { Suggestive } \\
\text { clinics } \\
\text { nNO } \\
\text { repeatedly low }\end{array}$ & $\begin{array}{c}\text { PCD highly } \\
\text { unlikely } \\
\text { HSVM ALI } \\
\text { normal } \\
\text { TEM } \\
\text { non-diagnostic } \\
\text { Genetics } \\
\text { negative }\end{array}$ & $\begin{array}{l}\text { PCD highly } \\
\text { unlikely } \\
\text { HSVM ALI } \\
\text { normal } \\
\text { TEM } \\
\text { non-diagnostic } \\
\text { Genetics } \\
\text { negative }\end{array}$ & $\mathrm{nNO}$ \\
\hline
\end{tabular}




\begin{tabular}{|c|c|c|c|c|c|c|c|c|c|c|c|c|c|c|}
\hline $\begin{array}{l}\text { Patient } \\
\text { number } \\
\text { (lab ID) }\end{array}$ & $\begin{array}{l}\text { Age at } \\
\text { referral } \\
\text { years }\end{array}$ & Sex & Clinical features & $\begin{array}{c}\mathrm{nNO} \\
\mathrm{nL} \cdot \mathrm{min}^{-1 \#}\end{array}$ & $\begin{array}{l}\text { HSVM fresh } \\
\text { (more details in } \\
\text { supplementary } \\
\text { table S1) }\end{array}$ & $\begin{array}{l}\text { HSVM ALI (more } \\
\text { details in } \\
\text { supplementary } \\
\text { table S1) }\end{array}$ & IF & $\begin{array}{c}\text { TEM } \\
\text { BEAT-PCD-TEM } \\
{[12]} \\
\text { classification }\end{array}$ & $\begin{array}{c}\text { Genetics } \\
\text { ACMG-classification } \\
{[27]}\end{array}$ & $\begin{array}{l}\text { Costs }^{f} \\
\text { EUR }\end{array}$ & Outcome ATS & Outcome ERS & $\begin{array}{l}\text { Outcome } \\
\text { PCD-UNIBE }\end{array}$ & $\begin{array}{l}\text { Main } \\
\text { tools } \\
\text { leading } \\
\text { to } \\
\text { diagnosis }\end{array}$ \\
\hline $17(294)$ & 5.0 & $f$ & $\begin{array}{l}\text { Chronic wet cough } \\
\text { Recurrent } \\
\text { respiratory tract } \\
\text { infections } \\
\text { Bronchiectasis }\end{array}$ & $\begin{array}{l}11 \\
12\end{array}$ & $\begin{array}{l}\text { No evidence for } \\
\text { PCD }\end{array}$ & $\begin{array}{l}\text { No evidence for } \\
\text { PCD }\end{array}$ & $\begin{array}{l}\text { No evidence } \\
\text { for PCD }\end{array}$ & - & $\begin{array}{l}\text { No likely pathogenic } \\
\text { or pathogenic variant } \\
\text { found in } 41 \text { genes } \\
\text { tested (2019) }\end{array}$ & 4930 & $\begin{array}{c}\text { PCD } \\
\text { diagnosed } \\
\text { Suggestive } \\
\text { clinics } \\
\text { nNO } \\
\text { repeatedly low }\end{array}$ & $\begin{array}{l}\text { PCD highly } \\
\text { unlikely } \\
\text { HSVM normal } \\
\text { Genetics } \\
\text { negative }\end{array}$ & $\begin{array}{l}\text { PCD highly } \\
\text { unlikely } \\
\text { HSVM normal } \\
\text { IF without } \\
\text { protein } \\
\text { missing } \\
\text { Genetics } \\
\text { negative }\end{array}$ & nNO \\
\hline $18(295)$ & 5.1 & $f$ & $\begin{array}{l}\text { Chronic cough } \\
\text { Recurrent } \\
\text { respiratory } \\
\text { tract infections } \\
\text { Recurrent otitis } \\
\text { media }\end{array}$ & $5^{4}$ & Inconclusive & $\begin{array}{c}\text { No evidence for } \\
\text { PCD }\end{array}$ & $\begin{array}{l}\text { All proteins } \\
\text { present }\end{array}$ & - & - & 1877 & $\begin{array}{c}\text { PCD } \\
\text { diagnosed } \\
\text { Suggestive } \\
\text { clinics } \\
\text { nNO low } \\
\text { (single } \\
\text { measurement) }\end{array}$ & $\begin{array}{l}\text { PCD highly } \\
\text { unlikely } \\
\text { HSVM normal }\end{array}$ & $\begin{array}{l}\text { PCD highly } \\
\text { unlikely } \\
\text { HSVM normal } \\
\text { IF without } \\
\text { protein } \\
\text { missing }\end{array}$ & nNO \\
\hline $19(319)$ & 6.5 & $\mathrm{~m}$ & $\begin{array}{l}\text { Premature birth } \\
\text { NRDS \& intensive } \\
\text { care admittance } \\
\text { Chronic rhinitis } \\
\text { Chronic cough } \\
\text { Recurrent bronchitis } \\
\text { Bronchopulmonary } \\
\text { dysplasia } \\
\text { OSAS }\end{array}$ & $\begin{array}{c}6.5^{\S} \\
41\end{array}$ & $\begin{array}{c}\text { No evidence for } \\
\text { PCD }\end{array}$ & Inconclusive & $\begin{array}{l}\text { No evidence } \\
\text { for PCD }\end{array}$ & $\begin{array}{l}\text { Non-diagnostic } \\
\text { (ALI) }\end{array}$ & $\begin{array}{c}\text { No likely pathogenic } \\
\text { or pathogenic variant } \\
\text { associated with PCD } \\
\text { found in } 6688 \text { genes } \\
\text { tested (2020) }\end{array}$ & 5855 & $\begin{array}{c}\text { PCD } \\
\text { diagnosed } \\
\text { Suggestive } \\
\text { clinics } \\
\text { nNO } \\
\text { repeatedly low }\end{array}$ & $\begin{array}{l}\text { PCD highly } \\
\text { unlikely } \\
\text { HSVM normal } \\
\text { TEM } \\
\text { non-diagnostic }\end{array}$ & $\begin{array}{l}\text { PCD highly } \\
\text { unlikely } \\
\text { HSVM normal } \\
\text { TEM } \\
\text { non-diagnostic } \\
\text { IF without } \\
\text { protein } \\
\text { missing }\end{array}$ & nNO \\
\hline
\end{tabular}

Single discordant outcome highlighted in italic letters. Bold text indicates results leading to a diagnosis of PCD and the final diagnosis. ACMG: American College of Medical Genetics and Genomics; ALI: air-liquid interface; ATS: American Thoracic Society; Array-CGH: array-based comparative genomic hybridisation; ERS: European Respiratory Society; f: female; HSVM: high-speed videomicroscopy; IDA: inner dynein arm; IF: immunofluorescence labelling; m: male; nNO: nasal nitric oxide; NRDS: neonatal respiratory distress syndrome; ODA: outer dynein arm; PCD: primary ciliary dyskinesia; PCD-UNIBE: comprehensive diagnostic centre at the University Children's Hospital, Inselspital Bern, Switzerland; TEM: transmission electron microscopy. \#: these are mean values for $\mathrm{nNO}$ for the right and left side. The unit for $\mathrm{nNO}$ results at our centre is parts per billion (ppb). To obtain values in $\mathrm{nL} \cdot \mathrm{min}^{-1}$ the formula (ppb) $\times$ sampling flow rate $\left(0.33 \mathrm{~mL} \cdot \mathrm{min}^{-1}\right.$ for Ecomedics Analyzer CLD $88 \mathrm{sp}$ ) was used as proposed in LEIGH et al. [18]. ": single nNO measurement. ${ }^{+}$: cystic fibrosis not excluded by sweat test or genetic testing. ${ }^{\S}$ : nNO measurement during rhinitis. ${ }^{f}$ : remark about the costs: the costs were estimated based on costs that are billed for each method performed (for costs of each method see supplementary table S2 and figure S1). The costs may be higher than in other studies; however, we have to consider that prices and salaries are usually higher in Switzerland compared to other countries. 

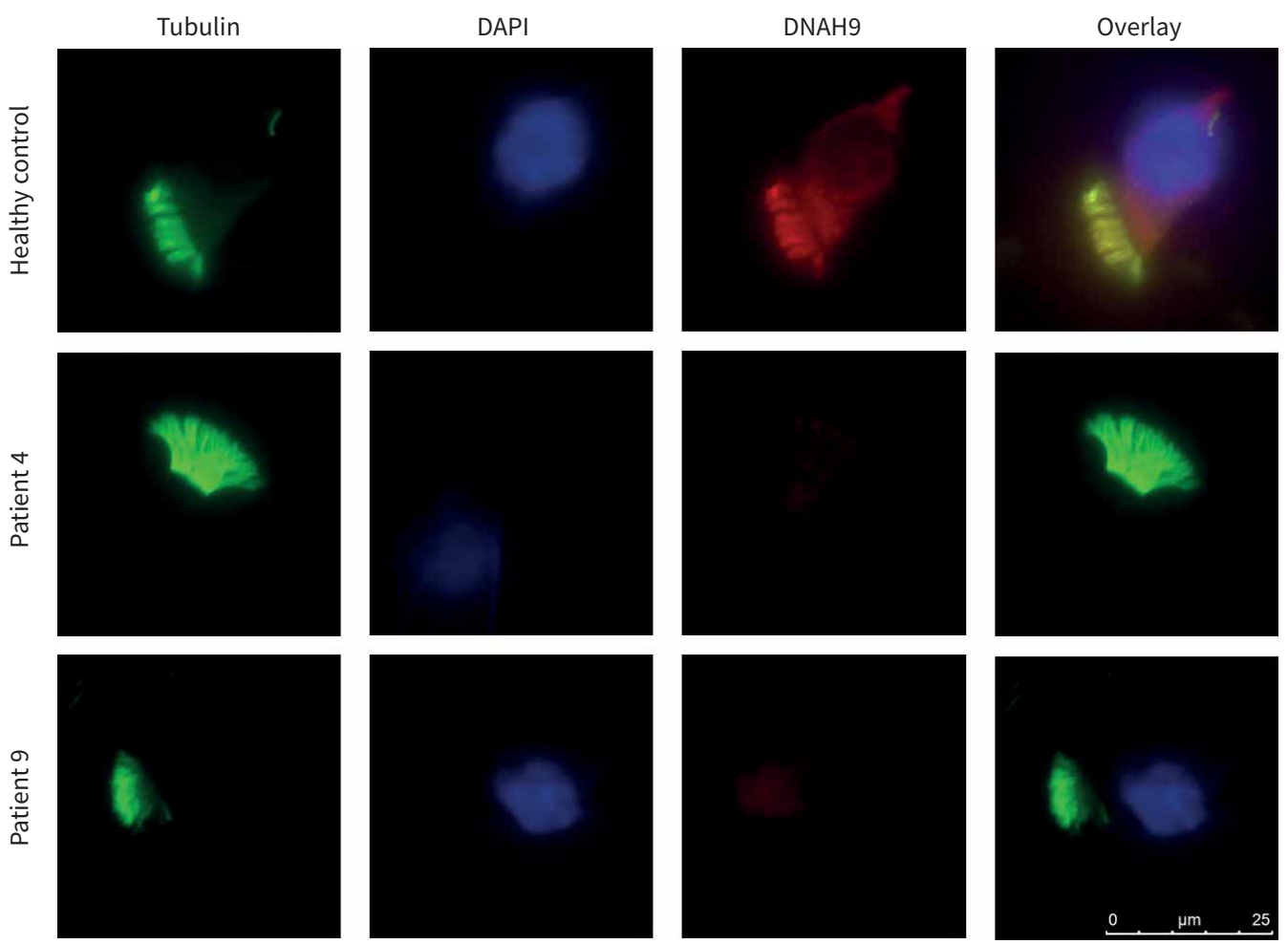

FIGURE 3 DNAH9 immunofluorescence staining of patients 4 and 9. Tubulin (green) is used as a reference, since it is present along all side of the ciliary axoneme. Diamidino-2-phenylindole (DAPI, blue) marks the cell nuclei. In patient number 4 DAPI staining was not successful; however, this does not affect the interpretation of the results. The target protein DNAH9 (red) is expected to be present in the distal part of the axoneme and is completely absent for both patients. The overlay of all three stainings confirms missing DNAH9 in both patients.

Agreement and concordance between the algorithms

While there was substantial agreement between the ERS and the ATS ( $\kappa=0.72,95 \%$ CI 0.53-0.92) as well as between the ATS and the PCD-UNIBE algorithms ( $\kappa=0.73,95 \%$ CI $0.53-0.92)$, the agreement between the ERS and the PCD-UNIBE algorithm was almost perfect ( $\kappa=0.92,95 \%$ CI $0.80-1.00)$ (table 3 ). Figure 5 shows the concordance for the three algorithms for all cases diagnosed with PCD according to at least one algorithm.

\section{Discussion}

Out of 54 patients included in this study, we found concordant diagnostic outcome according to all three algorithms for 46 patients (85\%, 30 without and 16 with PCD diagnosis) and discordant diagnostic outcome for eight patients. Thus, for $15 \%$ of the patients the diagnosis differed between algorithms. The agreement about the diagnosis was substantial for the ERS and the ATS as well as for the ATS and the PCD-UNIBE algorithms, and it was almost perfect for the ERS and the PCD-UNIBE algorithms.

With our finding of $15 \%$ of discordant diagnostic outcomes, we can confirm the already previously discussed theoretical differences between the ERS and the ATS algorithms [8, 10, 11], based on data from a real-life setting. The five cases (patients 15-19) that were only diagnosed based on reduced nNO according to the ATS algorithm support the doubts that $\mathrm{nNO}$ as sole investigation can diagnose PCD [2, $10,28-30]$. nNO has a sensitivity and specificity of $>95 \%$ compared with TEM or genetic testing when performed in children $>5$ years old with cystic fibrosis excluded [7, 18, 30]. However, a considerable risk for false negative [5, 10, 17] and false positive results [10, 17, 30, 31] remains. Besides the five cases diagnosed with PCD based on the ATS algorithm only ("false positive" compared with the ERS and PCD-UNIBE algorithms), we also found two patients with a "false negative" diagnosis based on the ATS algorithm (patients 4 and 14). Patient 14 was diagnosed by the ERS and PCD-UNIBE algorithms based on HSVM with rotating cilia (no PCD diagnosis according to ATS since normal nNO and TEM), while 


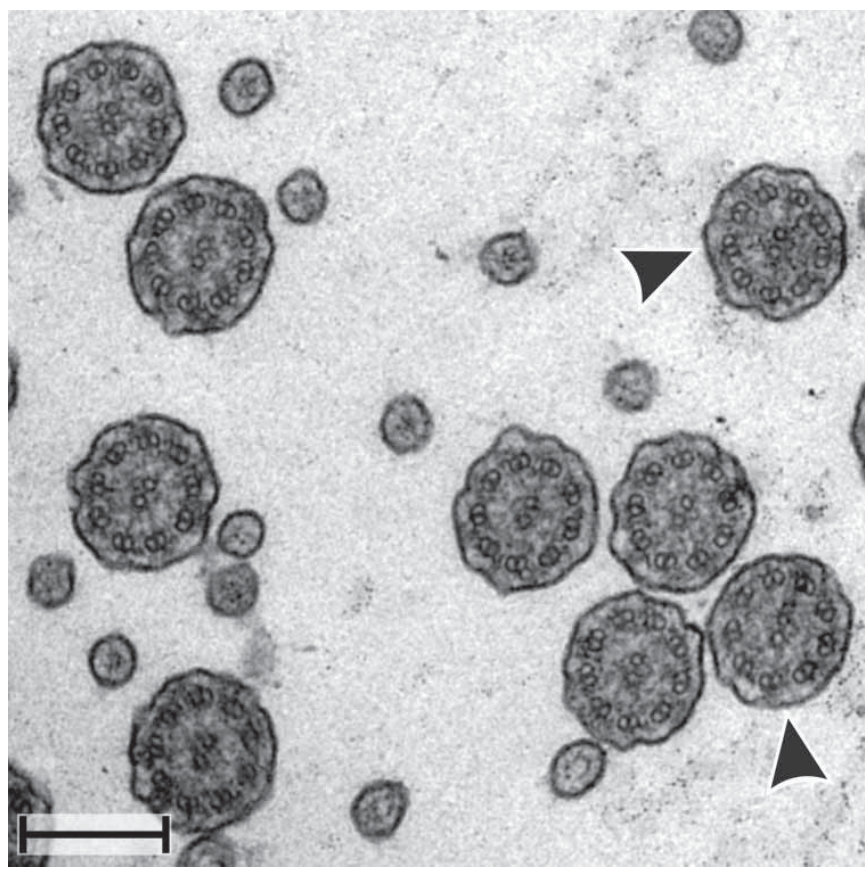

FIGURE 4 Transmission electron microscopy (TEM) image showing orthogonally sectioned cilia of patient 4. The axonemes at the arrowheads show shortened or missing outer (ODA, >4 of 9 affected) and inner (IDA, >6 of 9 affected) dynein arms. Scale bar: $250 \mathrm{~nm}$. Numerical analysis according to the published BEAT-PCD TEM criteria [12] are: ODA missing: 26.7\% (34.4\% proximal, 18.3\% distal). IDA missing: $19.2 \%$ (23.4\% proximal, $12.4 \%$ distal). Microtubular disorganisation: $1.6 \%$ missing peripheral tubuli. Central complex defect: $1 \%$ missing central tubuli, transposition defect: $2.6 \%$. Consistent ciliary orientation.

patient 4 was only diagnosed by the PCD-UNIBE (based on immunofluorescence and TEM), but not by the ERS or ATS algorithms. We therefore strongly support the suggestion of SHAPIRO et al. [30] to adapt the ATS algorithm and not use nNO as a sole investigation any longer.

Another important discussion within the PCD community has been the accuracy of HSVM for the PCD diagnostics [5, 7, 21, 29, 32, 33]. It has been shown that HSVM has good sensitivity and specificity to diagnose PCD when following standardised protocols [21] and has the advantage to provide a fast visualisation of the dyskinesia. In our study, the PCD diagnosis of four patients (patients 2, 3, 5 and 14) was mainly based on HSVM. For patients 3 and 5, genetics testing revealed biallelic mutations in the DNAH11 gene, but the clinical significance of the variants was unknown (according to the classification of the American College of Medical Genetics and Genomics (ACMG) [27]). For patient 2, only one heterozygote pathological variant in the DNAH11 gene was found. For all three patients with unclear DNAH11 mutations (all with a non-diagnostic TEM), the HSVM clearly showed a pathological beating pattern and led to the diagnosis of PCD. The fourth patient (patient 14) also had a non-diagnostic TEM but showed rotating cilia in the HSVM. Since we performed the HSVM with the fresh samples and with

TABLE 3 Agreement between the different diagnostic algorithms assessed by $\kappa$ statistics

\begin{tabular}{lccccccc} 
& $++^{*}$ & $+-{ }^{\star}$ & $-+^{+}$ & $--^{\S}$ & Total agreement & $\kappa$ & $95 \% \mathrm{Cl}$ \\
\hline ERS \& ATS & $16(30 \%)$ & $1(2 \%)$ & $6(11 \%)$ & $31(57 \%)$ & $47(87 \%)$ & 0.72 & $0.53-0.92$ \\
ERS \& PCD-UNIBE & $17(31 \%)$ & $0(0 \%)$ & $2(4 \%)$ & $35(65 \%)$ & $52(96 \%)$ & 0.92 & $0.80-1.00$ \\
ATS \& PCD-UNIBE & $17(31 \%)$ & $5(9 \%)$ & $2(4 \%)$ & $30(56 \%)$ & $47(87 \%)$ & 0.73 & $0.53-0.92$ \\
\hline
\end{tabular}

ERS: European Respiratory Society; ATS: American Thoracic Society; PCD-UNIBE: comprehensive diagnostic centre at the University Children's Hospital, Inselspital Bern, Switzerland. \#: both algorithms diagnosed PCD. ฯ: the algorithm listed first diagnosed PCD; the one listed second diagnosed no PCD. ${ }^{+}$: the algorithm listed first diagnosed no PCD; the one listed second diagnosed PCD. ${ }^{\S}$ : none of the algorithms diagnosed PCD. 


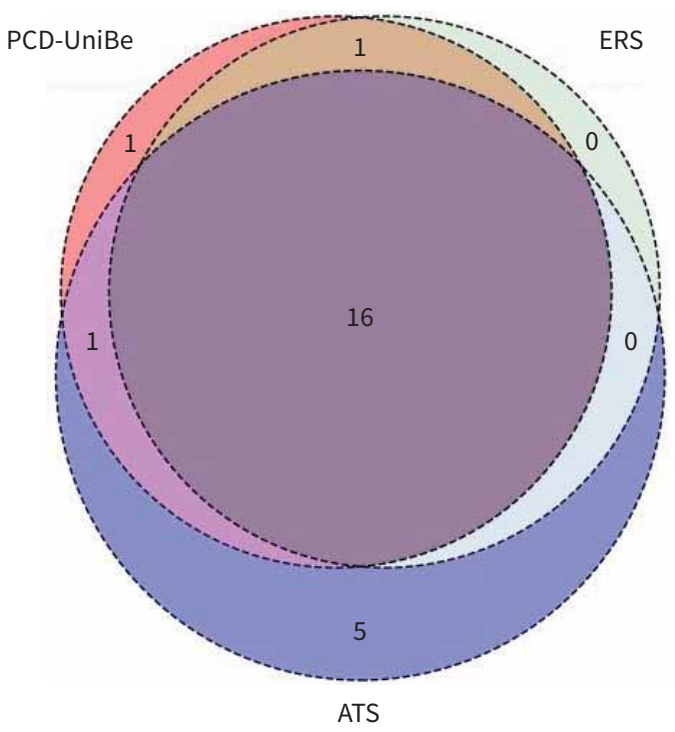

FIGURE 5 Venn diagram of patients with diagnosed primary ciliary dyskinesia (PCD) by the three different PCD diagnostic algorithms. Coloured circles represent the three different diagnostic algorithms. PCD-UNIBE algorithm (red); ERS algorithm (green); ATS algorithm (blue). Numbers listed represent patients with confirmed PCD; where circles overlap are common positive diagnosed PCD patients. 54 patients were included in the study and 30 were diagnosed without PCD by all three algorithms. This diagram shows the 24 cases that were diagnosed with PCD according to at least one algorithm. ATS: American Thoracic Society; ERS: European Respiratory Society.

the ALI cell culture or we repeat the nasal brushing at different time points, we can exclude secondary dyskinesia. Omitting HSVM from the diagnostic algorithm may thus lead to false negative diagnoses in cases with non-diagnostic TEM or unclear genetic results [5, 10, 21]. However, we agree that HSVM requires a high level of expertise and further standardisation of HSVM protocols is urgently needed [5, 7, $21,32,33]$.

Immunofluorescence is not part of both the ERS and the ATS algorithm [5, 7]. However, immunofluorescence is very specific and can be especially helpful in cases with normal ciliary ultrastructure (e.g. DNAH11 mutations) [13, 34, 35] or only subtle defects (e.g. DNAH9 mutations) in TEM [13, 24, 35]. Furthermore, according to the BEAT-PCD TEM criteria [12] immunofluorescence can be used to confirm a class 2 TEM defect. In our study, immunofluorescence was a key test in 12 patients (patients 2-6, 8, 9, 2024). Nine patients had missing DNAH11, two missing DNAH9 and one lacked several ODA proteins. In the cases with missing DNAH9, immunofluorescence was the most important method for diagnosing PCD. Considering the results of our study and taking into account that immunofluorescence requires less resources compared to TEM [36], we see many advantages of implementing immunofluorescence as part of the diagnostic workup and support SHOzmark and colleagues [13] in their demand to include immunofluorescence in a future diagnostic algorithm.

In our study, $44 \%$ of the included cases were diagnosed with PCD. This is a very high ratio compared to other centres, which usually confirm PCD in roughly $10 \%$ of the investigated cases [16]. There are three main reasons for this high prevalence: 1) our centre started in 2018 with a comprehensive approach, and as a consequence several previously unclear, but highly suspicious, cases from before were initially worked up (e.g. patients 1, 2, 8, 14, 16, 20-23); 2) there were two PCD families with three and four members (patients 10-12 and 20-23), respectively, that also contributed to the high prevalence; and 3) we included only cases with sufficient data to allow a final diagnosis on PCD based on all three algorithms. In our daily diagnostic workup, we only perform as many tests as needed to decide on a diagnosis. This implicates that we do not have results for all methods for every patient. Especially TEM and genetics are, due to high costs, not carried out if a PCD diagnosis is highly unlikely based on our basic investigations. This resulted in a selection bias towards PCD positive cases. The fact that we did not perform all methods for every patient is a clear weakness of the study. For single cases, the result of an additional method could change the outcome according to some algorithms (e.g. if patient 14 would not have refused genetic 
testing, a genetic mutation could have been identified and a PCD diagnosis according to the ATS guideline would be likely). Another weakness of the study is the small sample size. We could only include 54 patients, since we only had enough data for those to assess the diagnosis based on all algorithms. In order to address the cost issue in more detail, we calculated the costs for each case diagnosed with PCD (supplementary table S2). The costs for immunofluorescence and TEM reported here are higher than those previously reported [13]. The reasons are higher prices for consumables and higher salaries in Switzerland compared to other countries. Even though the diagnostics of PCD is quite costly, we are convinced that from a long-term perspective these costs, including the costs for the genetics, are justified with regards to a better understanding of the disease, to have the basics to develop causative and personalised treatments and to provide the patients with as much information about their specific disease as possible.

Although two consensus PCD diagnostic algorithms were recently published, diagnostics of PCD evolved quickly over the past few years, and most centres use their own updated and adapted diagnostic algorithm. In this study, we compared two published algorithms and our own (PCD-UNIBE). Our algorithm uses the most current diagnostic standards, including newer methods such as immunofluorescence and a standard use of ALI cell culture [3, 13, 37], and follows the recently published BEAT-PCD TEM criteria [12]. In our study, both immunofluorescence and ALI cell culture turned out to be crucial for many diagnoses. It is a clear strength of our study that we were able to assess the impact of including these recently developed procedures in our diagnostic algorithms by comparing our algorithm to currently existing guidelines. However, for those newer methods it will be important to also have international consensus standards. This is already in progress for immunofluorescence staining as part of BEAT-PCD [38] but is also needed for HSVM.

In $15 \%$ of the cases, the diagnostic outcome differed between the applied algorithms, leading to contradictory diagnoses for many patients. This may have consequences, for instance false positive PCD diagnoses can lead to psychological distress [39] and omission of specific treatments such as stem cell transplantation [30, 31]. Furthermore, it is very important for the patients to know their accurate diagnosis [39], and it can be crucial for claiming reimbursement of treatment costs by disability insurance (like in Switzerland). Finally, with regard to the real disease-altering treatment options currently being studied (e.g. CLEAN-PCD study, ClinicalTrials.gov Identifier: NCT02871778) it will be of great importance to know the underlying genetic mutations. Furthermore, with potential causative treatments in the future, we already now need to collect more data and gain a better understanding of the genotype-phenotype interactions. Besides the knowledge that some mutations (e.g. CCDC39/40) are associated with a more severe [40, 41] and some (e.g. DNAH9) with a milder [23, 42] disease course, we do not know a lot about differences in disease course based on the genotypes. PCD is a heterogeneous, genetic disease requiring complex diagnostics. Our study suggests that neither the ERS nor the ATS guidelines are sufficient for diagnosis; in some cases, extended investigations are needed. Our study shows that immunofluorescence and cell culture are important procedures in PCD diagnostics and should be additionally performed routinely. Diagnostic algorithms need to be continuously adapted according to the newest methods available. A single internationally accepted diagnostic algorithm would be an important step towards standardisation and facilitation of PCD diagnostics.

Acknowledgements: We thank all PCD patients and their families for allowing us to perform this study. We thank Andrea Stokes (Division of Paediatric Respiratory Medicine and Allergology, Department of Paediatrics, Inselspital, Bern University Hospital, and DBMR, University of Bern, Bern, Switzerland) and Beat Haenni (Institute of Anatomy, University of Bern, Bern, Switzerland) for their excellent laboratory work and helpful input. The study authors participate in the BEAT-PCD clinical research collaboration, supported by the European Respiratory Society. Our centre participates at the European Reference Network ERN Lung PCD core as a supporting member.

Provenance: Submitted article, peer reviewed.

Current Swiss PCD Research Group: Sylvain Blanchon (Dept Woman-Mother-Child, Service of Pediatrics, Pediatric Pulmonology and Cystic Fibrosis Unit, Lausanne University Hospital and University of Lausanne, Lausanne, Switzerland), Jean-Louis Blouin (Dept of Genetic Medicine and Development, University of Geneva, and Department of Genetic Medicine and Laboratory, University Hospitals of Geneva, Geneva, Switzerland), Marina Bullo, Carmen Casaulta (both Division of Paediatric Respiratory Medicine and Allergology, Dept of Paediatrics, Inselspital, Bern University Hospital, and DBMR, University of Bern, Bern, Switzerland), Myrofora Goutaki (Division of Paediatric Respiratory Medicine and Allergology, Dept of Paediatrics, Inselspital, Bern University Hospital, and Institute of Social and Preventive Medicine, University of Bern, Bern, Switzerland), Nicolas Gürtler (Pediatric Otorhinolaryngology, Dept of Otorhinolaryngology, University Hospital of Basel, Basel, Switzerland), Andreas Hector (Division of Respiratory Medicine, University Children's Hospital Zurich, Zurich, Switzerland), Michael Hitzler 
(Division of Paediatric Pulmonology, Children's Hospital Lucerne, Switzerland), Andreas Jung (Division of Respiratory Medicine, University Children's Hospital Zurich, Zurich, Switzerland), Lilian Junker (Pneumology, Hospital Thun, Thun, Switzerland), Elisabeth Kieninger (Division of Paediatric Respiratory Medicine and Allergology, Dept of Paediatrics, Inselspital, Bern University Hospital, and DBMR, University of Bern, Bern, Switzerland), Claudia E. Kuehni (Division of Paediatric Respiratory Medicine and Allergology, Dept of Paediatrics, Inselspital, Bern University Hospital, and Institute of Social and Preventive Medicine, University of Bern, Bern, Switzerland), Yin Ting Lam (Institute of Social and Preventive Medicine, University of Bern, Bern, Switzerland), Philipp Latzin (Division of Paediatric Respiratory Medicine and Allergology, Dept of Paediatrics, Inselspital, Bern University Hospital, and DBMR, University of Bern, Bern, Switzerland), Dagmar Lin (Dept of Pulmonary Medicine, Inselspital, Bern University Hospital, University of Bern, Bern, Switzerland), Loretta Müller (Division of Paediatric Respiratory Medicine and Allergology, Dept of Paediatrics, Inselspital, Bern University Hospital, and DBMR, University of Bern, Bern, Switzerland), Eva Pedersen (Institute of Social and Preventive Medicine, University of Bern, Bern, Switzerland), Nicolas Regamey (Division of Paediatric Pulmonology, Children's Hospital Lucerne, Lucerne, Switzerland), Isabelle Rochat (Dept Woman-Mother-Child, Service of Pediatrics, Pediatric Pulmonology and Cystic Fibrosis Unit, Lausanne University Hospital and University of Lausanne, Lausanne, Switzerland), Daniel Schilter, Iris Schmid, Bernhard Schwizer (all Quartier Bleu, Medical Practice for Pneumology at the Hospital Lindenhof, Bern, Switzerland), Andrea Stokes (Division of Paediatric Respiratory Medicine and Allergology, Dept of Paediatrics, Inselspital, Bern University Hospital, and DBMR, University of Bern, Bern, Switzerland), Daniel Tachsel (UKBB, Basel, Switzerland), Stefan A. Tschanz (Institute of Anatomy, University of Bern, Bern, Switzerland) and Johannes Wildhaber (Dept of Paediatrics, Fribourg Hospital HFR, Faculty of Science and Medicine, University of Fribourg, Fribourg, Switzerland).

Support statement: This study was supported by the Lung League Bern. Sibel T. Savas was supported by the German Academic Scholarship Foundation (Studienstiftung des Deutschen Volkes). Funding information for this article has been deposited with the Crossref Funder Registry.

Conflict of interest: M. Nussbaumer has nothing to disclose. E. Kieninger has nothing to disclose. S.A. Tschanz has nothing to disclose. S.T. Savas has nothing to disclose. C. Casaulta has nothing to disclose. M. Goutaki has nothing to disclose. S. Blanchon has nothing to disclose. A. Jung has nothing to disclose. N. Regamey has nothing to disclose. C.E. Kuehni has nothing to dislose. M. Goutaki has nothing to disclose. P. Latzin reports grants and personal fees from Vertex and Vifor, and personal fees from OM Pharma, Polyphor and Santhera (DMC), outside the submitted work. L. Müller has nothing to disclose.

\section{References}

$1 \quad$ Kuehni CE, Frischer T, Strippoli MP, et al. Factors influencing age at diagnosis of primary ciliary dyskinesia in European children. Eur Respir J 2010; 36: 1248-1258.

2 Amirav I, Lavie M. Reply to Shoemark, et al. and to Shapiro, et al. Am J Respir Crit Care Med 2020; 201: 123-125.

3 Lucas JS, Davis SD, Omran H, et al. Primary ciliary dyskinesia in the genomics age. Lancet Respir Med 2020; 8 : 202-216.

4 Goutaki M, Meier AB, Halbeisen FS, et al. Clinical manifestations in primary ciliary dyskinesia: systematic review and meta-analysis. Eur Respir J 2016; 48: 1081-1095.

5 Lucas JS, Barbato A, Collins SA, et al. European Respiratory Society guidelines for the diagnosis of primary ciliary dyskinesia. Eur Respir J 2017; 49: 1601090.

6 Boon M, Jorissen M, Proesmans M, et al. Primary ciliary dyskinesia, an orphan disease. Eur J Pediatr 2013; 172: 151-162.

7 Shapiro AJ, Davis SD, Polineni D, et al. Diagnosis of primary ciliary dyskinesia. An official American Thoracic Society clinical practice guideline. Am J Respir Crit Care Med 2018; 197: e24-e39.

8 Shoemark A, Dell S, Shapiro A, et al. ERS and ATS diagnostic guidelines for primary ciliary dyskinesia: similarities and differences in approach to diagnosis. Eur Respir J 2019; 54: 1901066.

9 Kuehni CE, Lucas JS. Diagnosis of primary ciliary dyskinesia: summary of the ERS Task Force report. Breathe (Sheff) 2017; 13: 166-178.

10 Shoemark A, Rubbo B, Haarman E, et al. The controversies and difficulties of diagnosing primary ciliary dyskinesia. Am J Respir Crit Care Med 2020; 201: 120-122.

11 Contarini M, Shoemark A, Rademacher J, et al. Why, when and how to investigate primary ciliary dyskinesia in adult patients with bronchiectasis. Multidiscip Respir Med 2018; 13(Suppl 1): 26.

12 Shoemark A, Boon M, Brochhausen C, et al. International consensus guideline for reporting transmission electron microscopy results in the diagnosis of Primary Ciliary Dyskinesia (BEAT PCD TEM Criteria). Eur Respir J 2020; 55: 1900725.

13 Shoemark A, Frost E, Dixon M, et al. Accuracy of immunofluorescence in the diagnosis of primary ciliary dyskinesia. Am J Respir Crit Care Med 2017; 196: 94-101. 
14 Coles JL, Thompson J, Horton KL, et al. A revised protocol for culture of airway epithelial cells as a diagnostic tool for primary ciliary dyskinesia. J Clin Med 2020; 9: 3753.

15 Usemann J, Alves MP, Ritz N, et al. Age-dependent response of the human nasal epithelium to rhinovirus infection. Eur Respir J 2020; 56: 2000877.

16 Behan L, Dimitrov BD, Kuehni CE, et al. PICADAR: a diagnostic predictive tool for primary ciliary dyskinesia. Eur Respir J 2016; 47: 1103-1112.

17 Shapiro AJ, Dell SD, Gaston B, et al. Nasal nitric oxide measurement in primary ciliary dyskinesia: a technical paper on standardized testing protocols. Ann Am Thorac Soc 2020; 17: e1-e12.

18 Leigh MW, Hazucha MJ, Chawla KK, et al. Standardizing nasal nitric oxide measurement as a test for primary ciliary dyskinesia. Ann Am Thorac Soc 2013; 10: 574-581.

19 Walker WT, Jackson CL, Lackie PM, et al. Nitric oxide in primary ciliary dyskinesia. Eur Respir J 2012; 40: 1024-1032.

20 Collins SA, Gove K, Walker W, et al. Nasal nitric oxide screening for primary ciliary dyskinesia: systematic review and meta-analysis. Eur Respir J 2014; 44: 1589-1599.

21 Rubbo B, Shoemark A, Jackson CL, et al. Accuracy of high-speed video analysis to diagnose primary ciliary dyskinesia. Chest 2019; 155: 1008-1017.

22 Kempeneers C, Seaton C, Garcia Espinosa B, et al. Ciliary functional analysis: beating a path towards standardization. Pediatr Pulmonol 2019; 54: 1627-1638.

23 Loges NT, Antony D, Maver A, et al. Recessive DNAH9 loss-of-function mutations cause laterality defects and subtle respiratory ciliary-beating defects. Am J Hum Genet 2018; 103: 995-1008.

24 Baz-Redon N, Rovira-Amigo S, Fernandez-Cancio M, et al. Immunofluorescence analysis as a diagnostic tool in a Spanish cohort of patients with suspected primary ciliary dyskinesia. J Clin Med 2020; 9: 3603.

25 Watson PF, Petrie A. Method agreement analysis: a review of correct methodology. Theriogenology 2010; 73: 1167-1179.

26 Hulsen T, de Vlieg J, Alkema W. BioVenn - a web application for the comparison and visualization of biological lists using area-proportional Venn diagrams. BMC Genomics 2008; 9: 488.

27 Richards S, Aziz N, Bale S, et al. Standards and guidelines for the interpretation of sequence variants: a joint consensus recommendation of the American College of Medical Genetics and Genomics and the Association for Molecular Pathology. Genet Med 2015; 17: 405-423.

28 Lucas JS, Rubbo B, Jackson CL, et al. Response. Chest 2019; 156: 1033-1034.

29 Lavie M, Amirav I. In defense of high-speed video microscopy in evaluating patients with suspected primary ciliary dyskinesia. Am J Respir Crit Care Med 2019; 200: 1181-1183.

30 Shapiro AJ, Davis SD, Leigh MW, et al. Limitations of nasal nitric oxide testing in primary ciliary dyskinesia. Am J Respir Crit Care Med 2020; 202: 476-477.

31 Zysman-Colman ZN, Kaspy KR, Alizadehfar R, et al. Nasal nitric oxide in primary immunodeficiency and primary ciliary dyskinesia: helping to distinguish between clinically similar diseases. J Clin Immunol 2019; 39: 216-224.

32 Shapiro AJ, Leigh MW, Omran $\mathrm{H}$, et al. Errors in methodology affect diagnostic accuracy of high-speed videomicroscopy analysis in primary ciliary dyskinesia. Chest 2019; 156: 1032-1033.

33 Shapiro AJ, Ferkol TW, Manion M, et al. High-speed videomicroscopy analysis presents limitations in diagnosis of primary ciliary dyskinesia. Am J Respir Crit Care Med 2020; 201: 122-123.

34 Dougherty GW, Loges NT, Klinkenbusch JA, et al. DNAH11 localization in the proximal region of respiratory cilia defines distinct outer dynein arm complexes. Am J Respir Cell Mol Biol 2016; 55: 213-224.

35 Wallmeier J, Nielsen KG, Kuehni CE, et al. Motile ciliopathies. Nat Rev Dis Primers 2020; 6: 77.

36 Rumman N, Jackson C, Collins S, et al. Diagnosis of primary ciliary dyskinesia: potential options for resource-limited countries. Eur Respir Rev 2017; 26: 160058.

37 Hirst RA, Jackson CL, Coles JL, et al. Culture of primary ciliary dyskinesia epithelial cells at air-liquid interface can alter ciliary phenotype but remains a robust and informative diagnostic aid. PLOS ONE 2014; 9: e89675.

38 Goutaki M, Crowley S, Dehlink E, et al. The BEAT-PCD (Better experimental approaches to treat primary ciliary dyskinesia) clinical research collaboration. Eur Respir J 2021; 57: 2004601.

39 Behan L, Dunn Galvin A, Rubbo B, et al. Diagnosing primary ciliary dyskinesia: an international patient perspective. Eur Respir J 2016; 48: 1096-1107.

40 Davis SD, Ferkol TW, Rosenfeld M, et al. Clinical features of childhood primary ciliary dyskinesia by genotype and ultrastructural phenotype. Am J Respir Crit Care Med 2015; 191: 316-324.

41 Davis SD, Rosenfeld M, Lee HS, et al. Primary ciliary dyskinesia: longitudinal study of lung disease by ultrastructure defect and genotype. Am J Respir Crit Care Med 2019; 199: 190-198.

42 Fassad MR, Shoemark A, Legendre M, et al. Mutations in outer dynein arm heavy chain DNAH9 cause motile cilia defects and situs inversus. Am J Hum Genet 2018; 103: 984-994. 